MICE Note 324

\title{
What Caused the Lead burn-out in Spectrometer Magnet 2B
}

\author{
Michael A. Green \\ Lawrence Berkeley National Laboratory
}

29 November 2010

\begin{abstract}
The spectrometer solenoids are supposed to be the first magnets installed in the MICE Cooling Channel [1] to [7]. The results of the test of Spectrometer Magnet 2B are reported in a previous MICE Note [8], [9]. Magnet 2B was tested with all five coils connected in series. The magnet failed because a lead to coil M2 failed before it could be trained to its full design current of 275 A. First, this report describes the condition of the magnet when the lead failure occurred. The lead that failed was between the cold mass feed-through and the heavy lead that connected to coil M2 and the quench protection diodes. It is believed that the lead failed because the minimum propagation zone (MPZ) length was too short. The quench was probably triggered by lead motion in the field external to the magnet center coil. The effect of heat transfer on quench propagation and MPZ length is discussed. The MPZ length is compared for a number of cases that apply to the spectrometer solenoid $2 \mathrm{~B}$ as built and as it has been repaired. The required heat transfer coefficient for cryogenic stability and the quench propagation velocity along the leads are compared for various parts of the Magnet leads inside the cold mass cryostat. The effect of the insulation on leads on heat transfer is and stability is discussed.
\end{abstract}

\section{Table of Contents}

$\begin{array}{lr}\text { Abstract } & 1 . \\ \text { Table of Contents } & 1 . \\ \text { Conditions that may have led to the M2 Coil Lead Break } & 2 . \\ \text { The Break in the M2 Lead in Spectrometer Solenoid 2B } & 4 . \\ \text { Adiabatic MPZ Length for Various Leads inside the Cold Mass } & 9 . \\ \text { Adiabatic Burn-out Time and Solder Melt time for Various Leads } & 12 . \\ \text { The effect of Transverse Heat Transfer on MPZ Length } & 14 . \\ \text { The Transverse Heat Transfer Coefficient needed for Cryogenic Stability } & 15 . \\ \text { The Effect of Lead Insulation on the Transverse Heat Transfer } & 19 . \\ \text { Adiabatic Quench Propagation Velocity along the Leads } & 22 . \\ \text { Changes made on the Magnet Leads and their Effect on Stability } & 24 . \\ \text { Other Issues found when the Magnet was Disassembled } & 25 . \\ \text { Coil Voltage and Current Measurements, and Other Issues } & 34 . \\ \text { Concluding Comments } & 35 . \\ \text { Acknowledgment } & 37 . \\ \text { References } & 37 .\end{array}$

Second revision on 27 February 2011 


\section{Conditions that may have led to the M2 Coil Lead Break}

Table 1 shows the temperatures and liquid levels in the cryostat just before the quench at $258 \mathrm{~A}$ that resulted in the break of the lead between the bottom of the HTS lead and the voltage tap to the coil. This quench occurred on 19 March 2010. The interpretation of the data given in Table 1 depends on where the lead break occurred.

Table 1. Temperature and liquid level data during the magnet charge of 19 March 2010.

\begin{tabular}{|l|c|c|c|}
\hline Time on 19 March 2010 (PST) & $\sim 15: 20$ & $\sim 15: 45$ & $\sim 16: 16$ \\
\hline Current in the Five Coils (A) & $\sim 140$ & $\sim 212$ & $\sim 250$ \\
\hline Cu Plate T at far end of Leads TPR3 (K) & $\mathbf{4 5 . 4 5}$ & $\mathbf{4 6 . 6 3}$ & $\mathbf{4 8 . 1 7}$ \\
\hline Cu Plate T near Cooler 1 TPR4 (K) & $\mathbf{5 0 . 5 3}$ & $\mathbf{5 0 . 4 9}$ & $\mathbf{5 0 . 7 5}$ \\
\hline Cu Plate T near Cooler 2 TPR5 (K) & No data & No data & No data \\
\hline Cu Plate T near Cooler 3 TPR6 (K) & $\mathbf{4 8 . 8 2}$ & $\mathbf{4 9 . 3 8}$ & $\mathbf{5 0 . 4 7}$ \\
\hline Shield T M1 End at Top TPR7 (K) & 87.87 & 87.42 & 87.22 \\
\hline Shield T E2 End at bottom TPR8 (K) & 98.55 & 98.51 & 98.45 \\
\hline T Outside of Cold Mass at E2 End TSD1 (K) & $\mathbf{4 . 5 3}$ & $\mathbf{4 . 6 1}$ & $\mathbf{4 . 9 7}$ \\
\hline T Outside Condenser 1 TSD2 (K) & 5.04 & 5.02 & 5.35 \\
\hline T Outside Condenser 2 TSD3 (K) & 4.78 & 4.89 & 5.29 \\
\hline T Outside Condenser 3 TSD4 (K) & 5.24 & 5.49 & 5.82 \\
\hline T inside Cryostat Bottom M1 End TRX1 (K) & $\mathbf{4 . 2 5 0}$ & $\mathbf{4 . 2 0 8}$ & $\mathbf{4 . 2 1 6}$ \\
\hline T inside Cryostat Top E2 End TRX2 (K) & $\mathbf{4 . 3 7 2}$ & $\mathbf{4 . 6 6 3}$ & $\mathbf{5 . 1 4 3}$ \\
\hline Liquid Level Lower Gauge (\%) & 99 & 99 & 99 \\
\hline Liquid Level Upper Gauge (\%) & $\sim 12.2$ & $\sim 6.9$ & $<0$ \\
\hline
\end{tabular}

At all currents shown in Table 1, there was gas where the cold mass feed-through was located. The temperature in the gas space at the top of the E2 end of the magnet cryostat is higher than the liquid temperature at the bottom of the magnet cryostat at the M1 end of the magnet. When the magnet cryostat is filled with liquid helium TRX1 is higher than TRX2, because the pressure at the bottom of the cryostat is higher than the pressure at the top of the cryostat. (On the saturated liquid line, a higher pressure corresponds to a higher temperature.) As the current increased, the temperature in the gas space increased. This is probably due to magnet coil AC loss heating [10] [11].

When the temperature rise from sensor TRX2 was first observed, it was thought that the temperature sensor might be faulty. What convinced us that the sensor was not faulty was the temperature measured on the outside of the cryostat near TRX2 using silicon diode sensor TSD1. The temperature measured by TSD1 went up, even though the apparent temperature measured by the diode should go down because of the magnetic field generated by the current in the magnet. There were similar temperature increases shown by sensors TSD2 through TSD4, which are located on the outside of the cooler stainless steel tubes near the stage- 2 condensers for all three coolers. 
Figure 1 shows the conductor load lines for a single conductor at three radii outside of the spectrometer solenoid center coil at $275 \mathrm{~A}$. At the peak field point inside the coil near the $\mathrm{E} 2$ end $\left(\mathrm{B}_{\mathrm{p}}=\sim 4.6 \mathrm{~T}\right)$, the critical temperature of the conductor is about $6.4 \mathrm{~K}$.

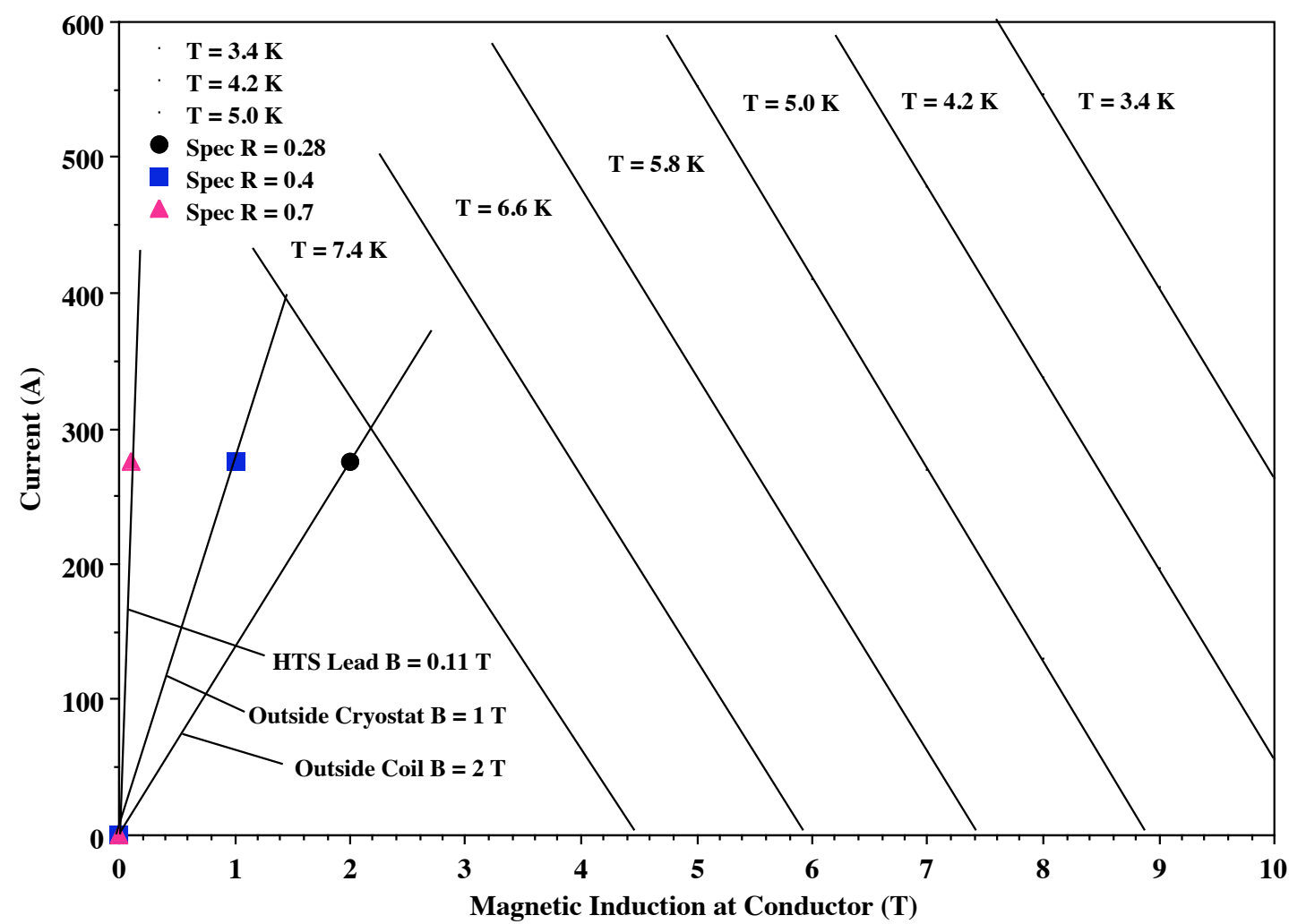

Figure 1. Conductor load lines for a single superconducting lead located outside of the center coil of the MICE spectrometer solenoid.

Figure 1 shows that the critical temperature of the niobium-titanium conductor is greater than $7.4 \mathrm{~K}$, even when the induction outside of the center coil is about $1 \mathrm{~T}$. The region at $0.5 \mathrm{~T}$ is just outside of the cold mass where the vacuum tight feed-through passes through the shell. The region that is at $0.2 \mathrm{~T}$ is at the low temperature end of the HTS leads for the spectrometer solenoid. At the top of the leads the induction is less than $0.1 \mathrm{~T}$. It is clear that temperature alone is very unlikely to be the cause of the failure of the M2 coil lead. It appears that some other factor led to the break of the M2 coil lead.

Rapid conductor motion in a magnetic field can cause AC losses in the conductor. If the conductor is poorly cooled, it is possible that the conductor temperature could become higher than its critical temperature over some length of the conductor that will allow the normal region to propagate along the lead wire. Conductor motion can be caused by magnetic forces. In much of the region in and around the diodes, the direction of the current in the conductor is the same as the magnetic field direction. These conductors are also well supported. In the region on the helium side of the feed-through, there is the potential for conductor motion due to Lorenz forces; because flexibility was built into the system to enable the magnet leads to be connected to the feed-through during the magnet assembly. The conductor leading to the feed-through was small in cross-section. 
Since the region between the outer surface of the center coil and the outside of the feed-through is at a magnetic induction of 0.5 to $1 \mathrm{~T}$, there is the ability to generate $\mathrm{I} \times \mathrm{B}$ forces as high as $275 \mathrm{~N} / \mathrm{m}$ in the wire. The unsupported length of wire is supposed to be short, but there is the possibility that such forces could generate enough conductor motion to result in a wire quench. If there is a short length of thin lead wire, a normal region long enough to propagate along the wire can develop and cause the wire to burn out.

Because the cold mass moves with respect to the bottom of the HTS leads during the magnet cool-down, there must be some flexibility between the bottom of the HTS leads and the top of the structure that carries the magnet leads between the vacuum side of the feed-through and the HTS leads. The field in this region is much lower than it is around the feed-through that goes into the magnet helium tank. Since the magnetic field is lower $(\sim 0.15$ to $0.2 \mathrm{~T})$, the forces are much lower (less than $50 \mathrm{~N} / \mathrm{m})$ in this region. If the failure occurred in this region, it seems unlikely that the elevated temperature of the gas in the upper part of the cryostat had anything to do with the lead failure. The lead failure didn't occur in this region, but it may have been possible for a short section of lead outside of the feed through to turn normal. The lead outside of the cold mass feedthrough was better supported than the lead inside of the cold mass feed-through.

It is unlikely that a quench of the magnet (with all coils connected in series) caused the lead to coil M2 to fail. In order for this to happen, the quench must propagate to the lead that failed. When the magnet quenches, the current decays to zero in roughly $5 \mathrm{~s}$. If the M2 coil lead went normal due to the magnet quench, its current would also decay is about $5 \mathrm{~s}$. Even at the full design current for the spectrometer magnet, the heating in the lead is very unlikely to be hot enough to melt the copper in the lead.

In general, it is implausible that the heating at the top of the helium vessel was the direct cause of the M2 lead failure. The increased temperature in the top of the gas space around coil E2 was caused by coil AC losses and poor cooling. Heating due to conductor motion in a magnetic field appears to be the cause of the conductor failure in the M2 coil circuit. Since the failure of the M2 lead occurred inside of the cold mass helium vessel, poor cooling of the conductor in helium gas could be a contributing factor to the lead failure, but it is not the cause of the failure. This will be discussed later.

\section{The Break in the M2 Lead in Spectrometer Solenoid 2B}

After magnet 2B with all five coils connected in series was quenched at $258 \mathrm{~A}$, the magnet was cooled down to $4 \mathrm{~K}$ and the cold mass helium tank was filled. When we tried to charge the magnet, the power supply went to the designated charging voltage; the magnet carried no current. The external circuits were checked to see that there were no cables disconnected. There were no breaks in the external circuit. The cables were disconnected so that one could measure the resistance of each of the five coils. All of the spectrometer solenoid coils had zero resistance, except coil M2, which was an open circuit. It was clear that there was a break in the M2 coil circuit and that the break was inside of the cryostat vacuum vessel. Using the voltage taps in the M2 coil circuit, we were able to determine which part to the magnet circuit was broken. The break in the M2 coil circuit occurred between the bottom of one of the HTS leads and the point in the coil circuit where the back-to-back diodes and resistor were connected to the coil. It was

clear that the coil itself was not damaged. The section of the M2 coil circuit where the break occurred is illustrated schematically in Figure 2. 


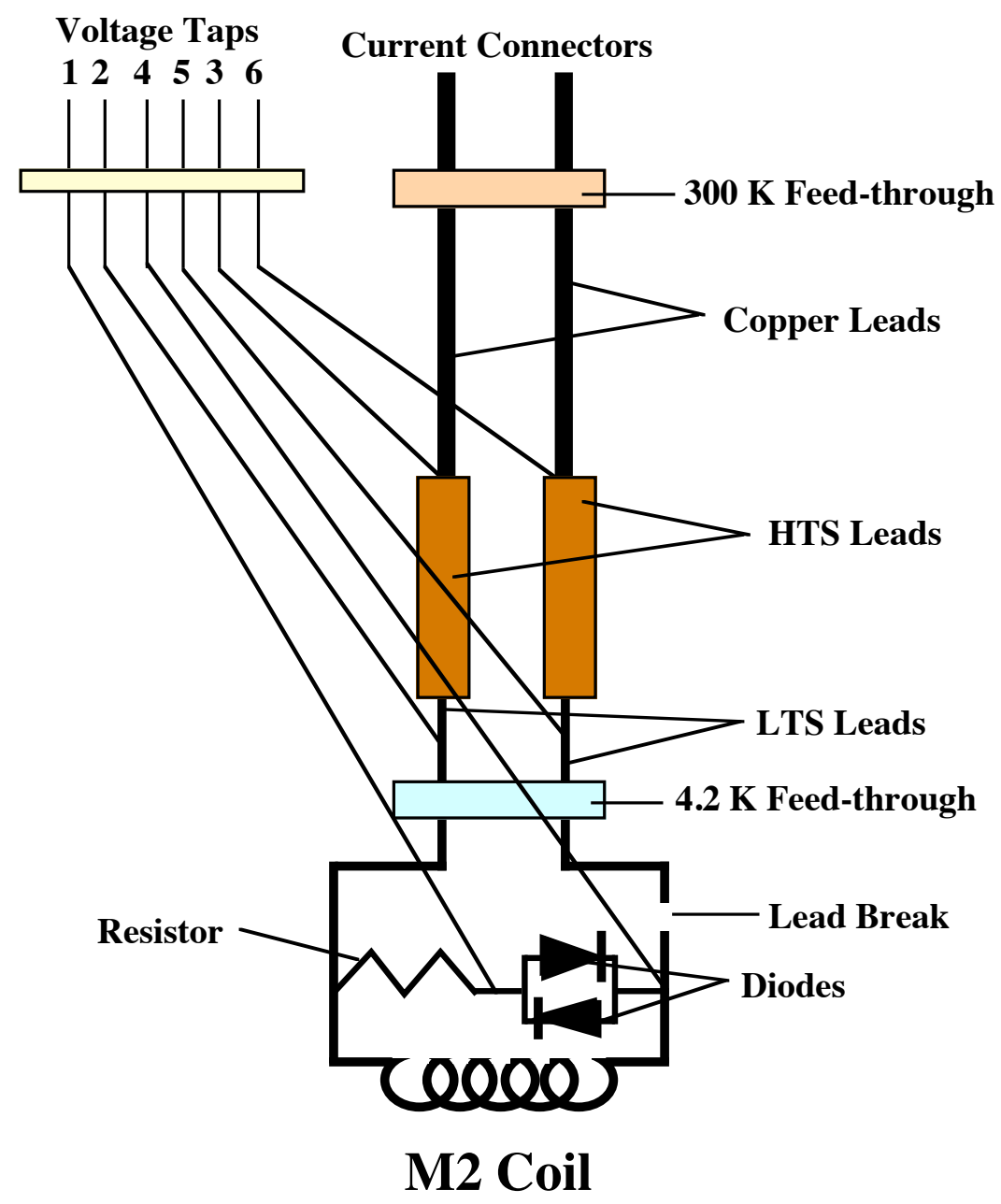

Figure 2. An Electrical Schematic of the M2 Coil Circuit with its Six Voltage Taps. (Note: the current surge protection resistors on the voltage taps are not shown.)

The turret region of the magnet $2 \mathrm{~B}$ was carefully disassembled so that we could find the break in the M2 coil circuit, if it occurred outside of the magnet cold mass. It became clear that the break did not occur outside of the cold mass. This was unlikely to be the case, because of the length of unsupported superconductor between the cold mass vacuum tight $4.2 \mathrm{~K}$ feed-through and the spreader that carried the LTS leads to the bottom of the HTS leads was very short. The spreader, which is conduction cooled from the cold mass helium tank formed a stiff support that should prevent motion of the superconductor coming out of the $4.2 \mathrm{~K}$ feed-through.

The author of this note suspected that the conductor break in the M2 coil circuit was the single piece of SSC inner superconductor that soldered into the $4.2 \mathrm{~K}$ vacuum tight feed-through in the liquid helium tank. It was clear that the failure did not occur inside of the feed-trough, because the feed-through didn't leak after the M2 coil circuit failed. When the cold mass was cut open, the lead failure could be seen. The wire used for the SSC inner cable had failed at a point roughly half between the feed through and the point where two pieces of the coil conductor connected to the feed-through conductor. 
The conductor that failed is shown in Figure 3. The diameter of the conductor that failed was $1.32 \mathrm{~mm}$ not the $0.80 \mathrm{~mm}$ diameter of the SSC inner conductor before it was cabled. When the vendor told us that this conductor was SSC inner conductor we thought it was the conductor used before it was cabled. The $0.8 \mathrm{~mm}$ diameter conductor can carry about $600 \mathrm{~A}$ at $5 \mathrm{~T}$ and $4.2 \mathrm{~K}$. The vendor used SSC inner conductor that was one or two draws from its final dimension of $0.80 \mathrm{~mm}$. The $1.32 \mathrm{~mm}$ diameter conductor used by the vendor can carry at least $1200 \mathrm{~A}$ at $5 \mathrm{~T}$ and $4.2 \mathrm{~K}$. At $275 \mathrm{~A}$, at an induction of $1 \mathrm{~T}$, the critical temperature of this conductor is over $8 \mathrm{~K}$. The failure was not caused by excessive temperature in the cryostat. Poor heat transfer to the $5.1 \mathrm{~K}$ helium gas in the top of the cryostat may have been a factor, but the gas temperature itself was not a factor.

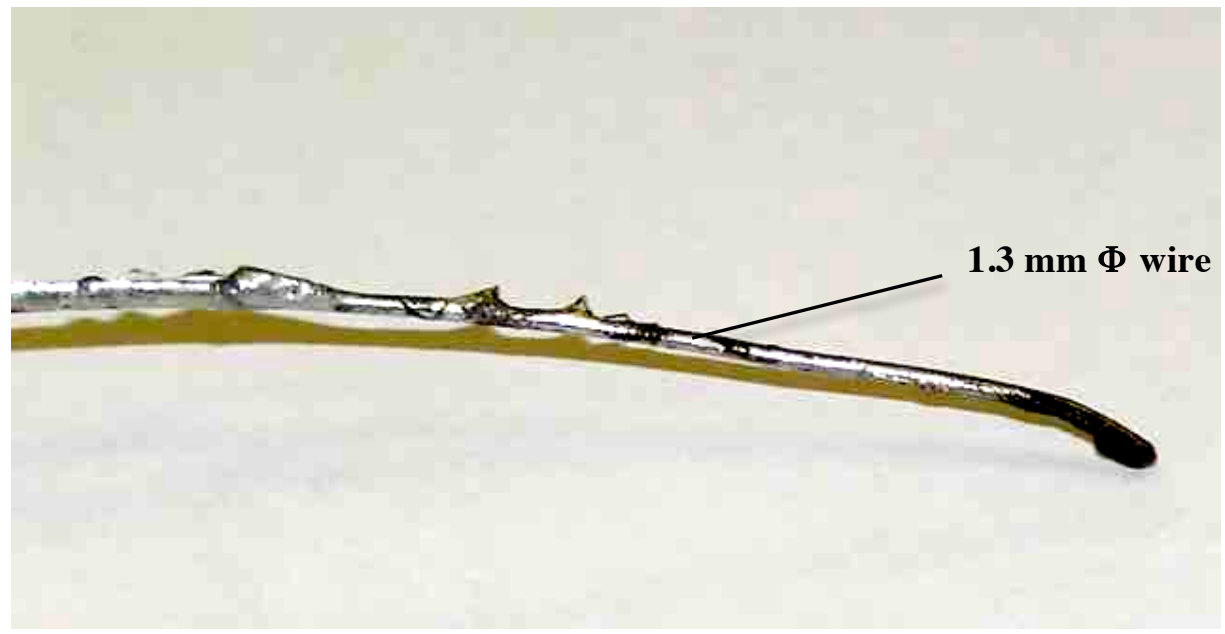

Figure 3. The Conductor that failed in the M2 Coil Circuit

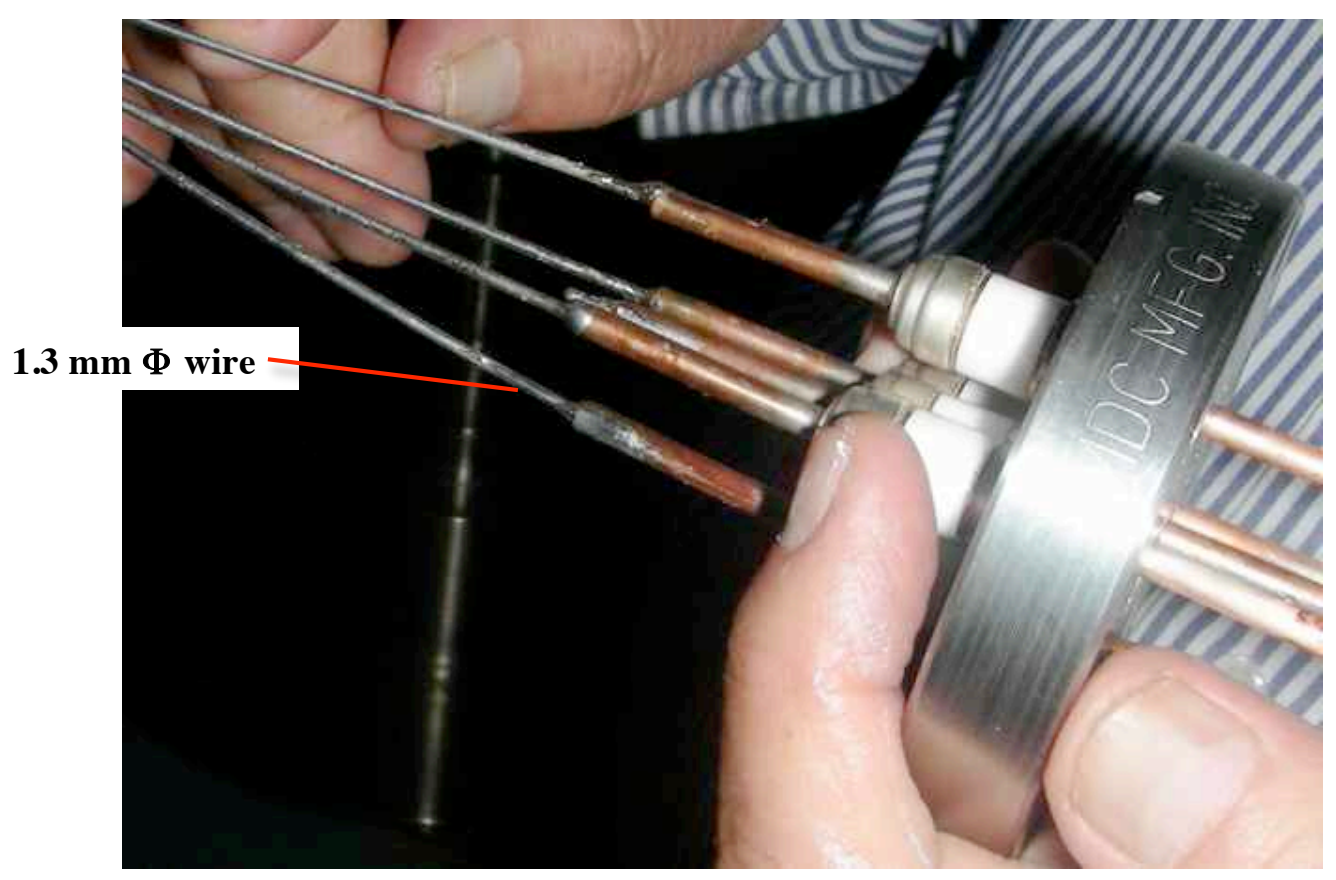

Figure 4. The Cold Mass Vacuum Tight Feed-through showing the Insulator (Liquid Helium) Side 
Figure 4 shows the inside (the insulator side that is in liquid helium) of the vacuum tight feed-through for the superconducting leads that go to the coils from the vacuum space in the cryostat. Figure 5 below shows the outside (the vacuum side) of the feedthrough. The feed-through is a standard feed-through that has been modified by the vendor so that the superconductor can pass through $3.18 \mathrm{~mm}$ diameter copper pins in the feed-through. The spectrometer solenoid has two of these feed-through for the magnet leads. One feed-through carries the 300 A cold current busses for coils M1 and M2. The second feed-through carries two 300 A cold current busses for the three coil set (E1, center and E2) and the $60 \mathrm{~A}$ current busses that are used to power the correction coils that are across coils E1 and E2.

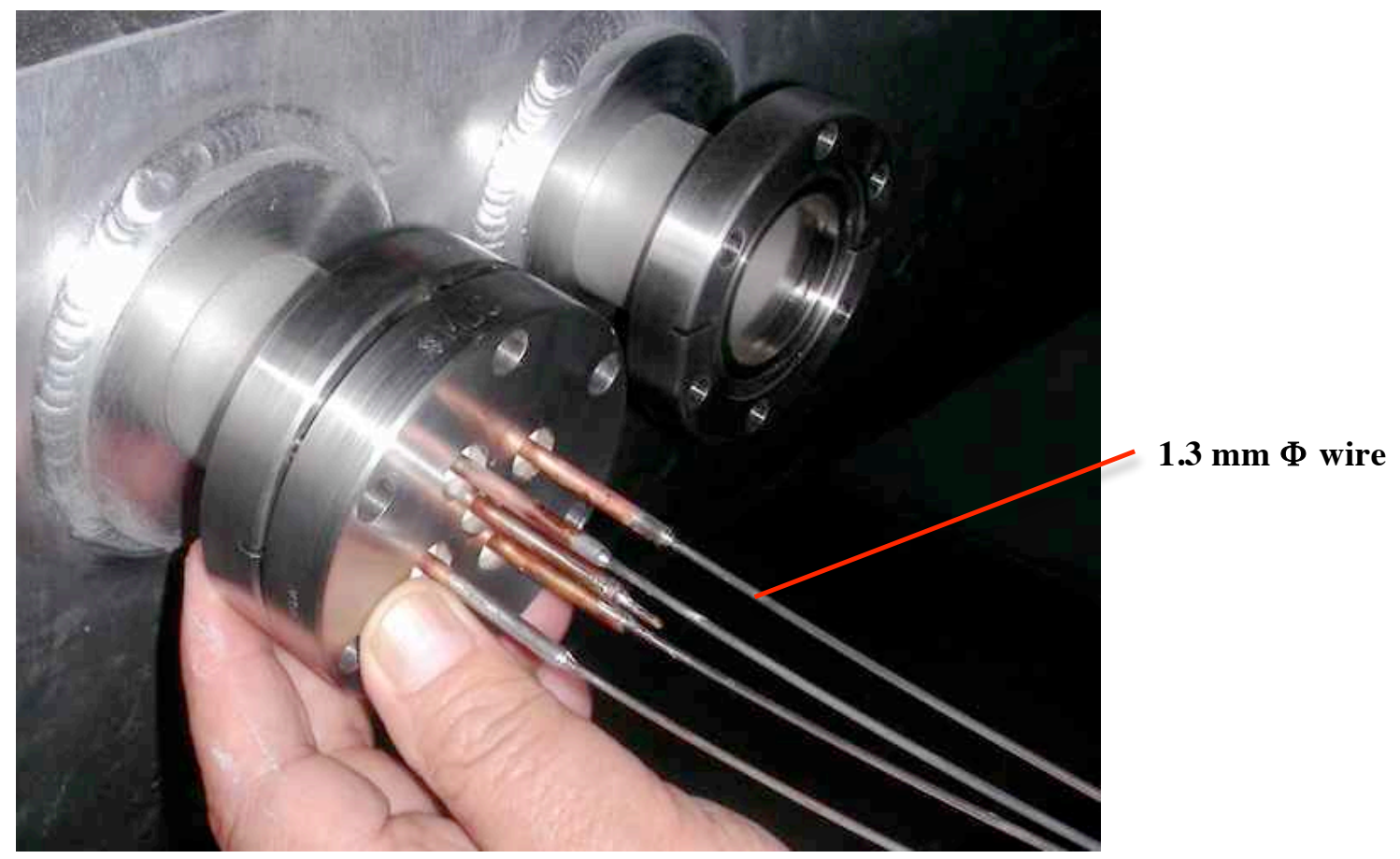

Figure 5. The Cold Mass Vacuum Tight Feed-through from the Vacuum Side

There is added superconductor soldered to both ends of thin wire that goes through the pins of the feed-through. On both sides the conductor consists of a pair of 0.95 by $1.60 \mathrm{~mm}$ conductors. This is the same conductor that was wound into the coils. These conductors have a copper to superconductor ratio of 4 . Each conductor can carry at least $760 \mathrm{~A}$ at $5 \mathrm{~T}$ and $4.2 \mathrm{~K}$. The SCC inner wire that goes through the feed-through pins has a copper to superconductor ratio of 1.4. The added conductor on either side of the feedthrough provides mechanical support and added current carrying capacity. The reinforced leads operate at a lower current density than the coil or the wire that goes through the feed-through. Operation at a lower current density is key to making the superconducting busses resistant to quenches that might be induced by small conductor movements. The vendor didn't extend the extra conductor all the way to the pins that go through the feed-through. The vendor was afraid to melt the solder in the feed-through pins. In addition, on the inside the vendor wanted added flexibility. This was probably the mistake that caused the lead to fail. 
The connection of the extra wires on the outside of the feed-through was different than the connection of the wires on the inside of the feed-through. The unreinforced section of wire on the outside ranged in length fro 15 to $20 \mathrm{~mm}$. While the 15 to $20 \mathrm{~mm}$ length of thin wire was unsupported mechanically, it was rigidly supported at each end. The feed-through pins provided support at one end, and the other end was supported to the conduction cooled spreader plate connected directly to the cold mass. Since the unsupported length of wire is quite short there isn't enough length to provide enough force to cause the wires outside of the feed-through to move enough to quench. The feed-through and spreader plate connections are shown in Figure 6.

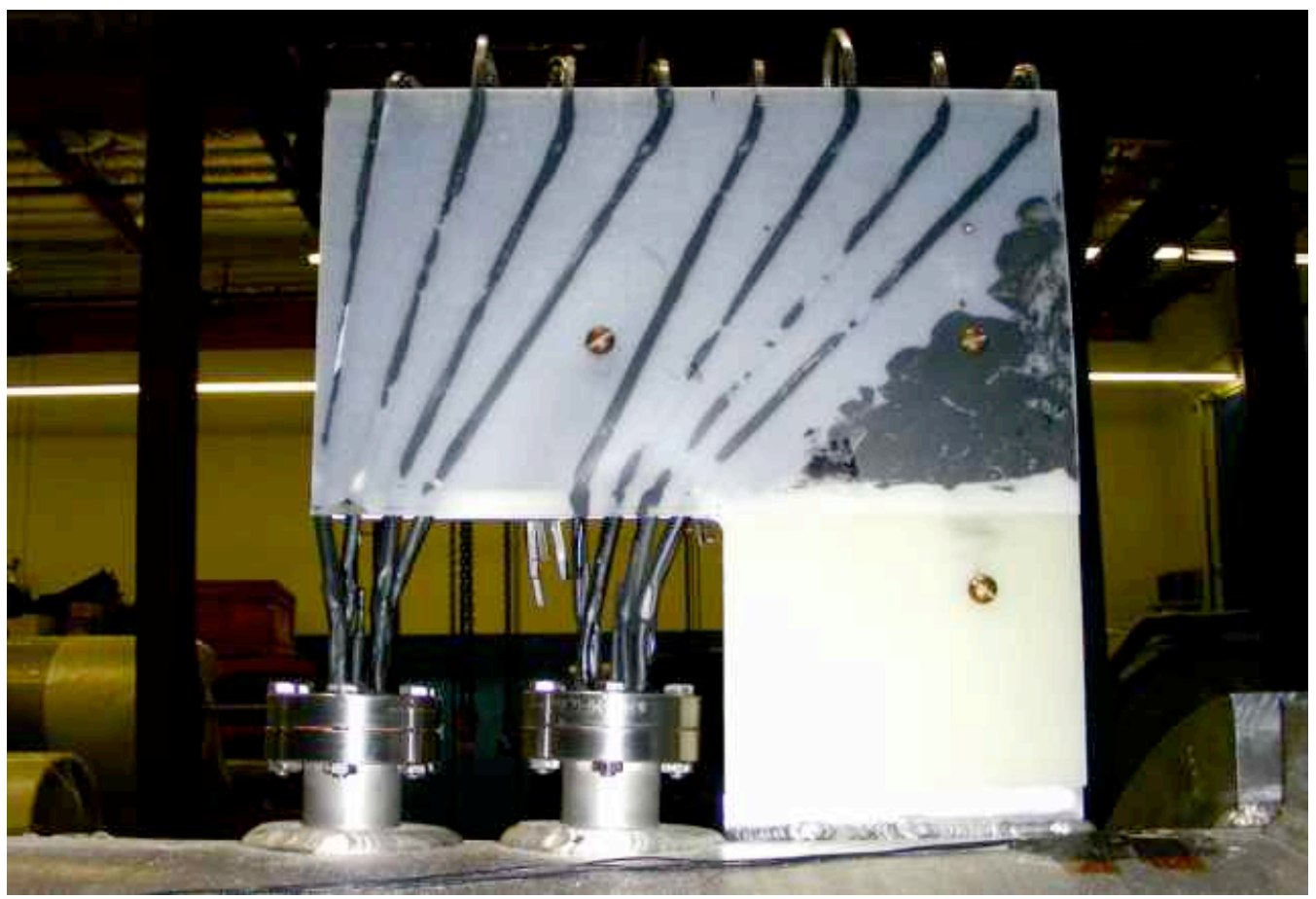

Figure 6. The Spreader Plate for Magnet 2 and its Connection to the Cold Mass and Lead Feed-throughs (The left feed-through has the leads for coils M1 and M2; the right feed-through has the leads for the threecoil set (E1, center and E2) that produces the uniform field for the MICE trackers.)

The reinforced leads (two standard conductors plus the SSC inner wire) that are inside of the feed-through have a much longer unsupported section (300 to $350 \mathrm{~mm}$ ). Much of the unsupported section goes in the direction of the magnetic field. This section of the unreinforced single wire lead is also longer $(50$ to $70 \mathrm{~mm})$. The combination of a longer unsupported length and unreinforced length allowed the leads to be connected to the feed-through and the feed-through to be made up. It is likely that the extra flexibility allowed the bare SSC inner wire to move fast enough so that a short section of the wire could turn normal due to conductor motion in the magnetic field. When the feed-through was assembled, the LTS conductors that were connected to the feed-through appeared to be stiff enough that they would not move. If the leads moved enough in the magnetic field and the lead MPZ length is short, a quench in the wire could occur. It is unlikely that this quench would propagate into the coil to cause the coil to quench. 


\section{Adiabatic MPZ Length for Various Leads inside the Cold Mass}

The concept of having a minimum propagation zone MPZ length was first presented in the 1970's [12], [13]. The MPZ length is the length at which a quench propagates. If the section of the conductor that is normal is less than the MPZ length, the heat will be conducted away along the conductor faster than it is generated by $\mathrm{I}^{2} \mathrm{R}$ heating within the section that is normal. The definition of the adiabatic MPZ length is the MPZ length where heat transfer only occurs along the wire at the normal zone ends. If there is transverse heat transfer, (in other directions besides along the wire) the MPZ length is longer. Wilson uses the concept of MPZ length to illustrate why wires made with pure superconductor (with little or no copper) quench easily [14]. This phenomenon was certainly observed in the early magnets built using type II superconductors. The addition of copper to a conductor greatly increased the MPZ length and the energy needed to cause the conductor to quench. The copper also dampens magnetic flux change [15].

If a section of superconducting wire becomes normal, heat will be generated in the conductor. This heat travels along the conductor and is conducted away at the ends of the normal zone. The heat generated is proportional to the length of the normal zone L, the across section area $A_{c}$ and the normal metal resistivity $\rho$. The heat conducted away from the normal zone is proportional to the product of the thermal conductivity $\mathrm{k}$ and the cross-section area $A_{c}$ and it is inversely proportional to the $\mathrm{L}$. The heat balance equation given by Wilson [14] is as follows;

$$
\frac{2 k A_{c}\left(T_{c}-T_{o}\right)}{L}=J_{c}^{2} \rho A_{c} L
$$

where $T_{c}$ is the conductor critical temperature and $T_{o}$ is the operating temperature of the conductor. The normal zone length is $\mathrm{L}$. If the normal region length $\mathrm{L}$ is shorter than some critical value, the left side of the equation will always be larger than the right side of the equation. This means that more heat is being taken away than is generated, so the normal region will shrink. If the length is larger than the critical value, the heat generated is greater than the heat conducted away. This means that the normal region will grow, hence the process of quenching will propagate along the wire.

The critical length is defined as the minimum propagation zone length $\mathrm{L}_{\mathrm{MPZ}}$. The MPZ length is defined as follows;

$$
L_{M P Z}=\left[\frac{2 k\left(T_{c}-T_{o}\right)}{J_{c}^{2} \rho}\right]^{0.5}
$$

If a disturbance causes a length of conductor longer than $\mathrm{L}_{\mathrm{MPZ}}$ to turn normal, the normal region will propagate along the wire. If a disturbance causes a length the conductor shorter than $\mathrm{L}_{\mathrm{MPZ}}$ to turn normal, this normal region will not propagate. The conductor will return to the superconducting state. For a conductor made of pure niobium titanium at $5 \mathrm{~T}, \mathrm{~J}_{\mathrm{c}}=2.5 \times 10^{9} \mathrm{~A} \mathrm{~m}^{-2}, \rho=6.5 \times 10^{-7} \Omega \mathrm{m}$, and $\mathrm{k}=0.16 \mathrm{~W} \mathrm{~m}^{-1} \mathrm{~K}^{-1}$. The conductor $\mathrm{T}_{\mathrm{c}}=6.5 \mathrm{~K}$ and the operating temperature $\mathrm{T}_{\mathrm{o}}=4.2 \mathrm{~K}$. For pure niobium titanium, the minimum propagation zone length is $0.425 \mu \mathrm{m}$, which explains why early superconducting magnets were so unstable. Adding copper to the conductor reduced the $I_{c}$ and $T_{c}$, but it greatly increased the $k / \rho$, which increases the conductor MPZ length. 
The MPZ length equation can be applied to modern composite conductors with a matrix material (pure $\mathrm{Cu}$ or pure $\mathrm{Al}$ ) and superconductor. When one applies Equation 2 to composite conductors, the current and heat are assumed to be carried by the matrix material. Thus the effective values of $\mathrm{k}$ and $\mathrm{J}$ are given as follows;

$$
\begin{array}{ll}
k_{e f}=k_{M} \frac{r}{r+1}, \text { and } & -3 \mathrm{a}- \\
J_{M}=\frac{I}{A_{c}} \frac{r+1}{r}, & -3 \mathrm{~b}-
\end{array}
$$

where $r$ is the matrix to superconductor ratio, $I$ is the conductor current and $A_{c}$ is the conductor cross-section area.

One can estimate the thermal conductivity $\mathrm{k}$ of a metal if one knows its electrical resistivity $\rho$ using the Wiedeman and Franz equation given below;

$$
k \rho=L_{O} T
$$

where $\mathrm{L}_{\mathrm{O}}$ is the Lorenz number $\left(\mathrm{L}_{\mathrm{O}}=2.45 \times 10^{-8} \mathrm{~W} \Omega \mathrm{K}^{-2}\right)$ and $\mathrm{T}$ is temperature. If one assumes that $\rho$ is constant at low temperatures (say $<15 \mathrm{~K}$ ), one can get a simple equation for the MPZ length for a composite conductor that is only a function of $J_{M}, r, \rho_{M}, T_{c}$ and $\mathrm{T}_{\mathrm{o}}$. The minimum propagations zone length equation for a composite conductor takes the following form;

$$
L_{M P Z}=\left[\frac{L_{O}\left(T_{c}^{2}-T_{o}^{2}\right)}{\left(J_{M} \rho_{M}\right)^{2}}\left(\frac{r}{r+1}\right)^{3}\right]^{0.5},
$$

where $J_{M}=I / A_{c}$, and $\rho_{M}$ is the matrix material resistivity. If one wants to have a long MPZ length, one must have a low resistivity matrix material, a large value of $r$ and a low current density $\mathrm{J}_{\mathrm{M}}$ across the conductor cross-section. The pure-aluminum stabilized conductors for detector magnet have very long MPZ lengths, because $J_{M}$ and $\rho_{M}$ are both low. (A typical detector magnet has $\mathrm{J}_{\mathrm{M}}=\sim 10^{7} \mathrm{~A} \mathrm{~m}^{-2} ; \rho_{\mathrm{M}}=\sim 10^{-11} \Omega \mathrm{m}$; and $\mathrm{r}=100$. The MPZ length for such a conductor is $\sim 4.3$ meters.) Conductors with large MPZ lengths require much higher energies to induce a quench.

The energy needed to induce a quench can be estimated using the following expression;

$$
Q E=L_{M P Z} A_{c} \Delta H,
$$

where $\mathrm{QE}$ is the quench energy and $\Delta \mathrm{H}=\mathrm{C}\left(\mathrm{T}_{\mathrm{c}}-\mathrm{T}_{\mathrm{o}}\right)$ with $\mathrm{C}$ the volume specific heat. If one applies Equation 6 to pure Nb-Ti conductor with $\mathrm{A}_{\mathrm{c}}=10^{-6} \mathrm{~m}^{2}$ and $\Delta \mathrm{H}=6 \times 10^{4} \mathrm{~J} \mathrm{~m}^{-3}$, one calculates a quench energy of $2.02 \times 10^{-9} \mathrm{~J}$. By comparison, the quench energy for a composite conductor can be from three to ten orders of magnitude higher depending on the overall conductor current density $\mathrm{J}_{\mathrm{M}}$ and the resistivity of the matrix material $\rho_{\mathrm{M}}$. The quench initiation energy is lower for superconductors with a low normal metal to superconductor ratio $\mathrm{r}$. The importance having a lot of low resistivity matrix material in a superconductor cannot be overstated. 
Table 2. compares the lead MPZ length for five cases at a current of 275 A (the design current for the spectrometer solenoid). The quench initiation energy at $275 \mathrm{~A}$ is also compared for the same cases. The five conductor cases are as follows:

Case 0: This is the SSC Inner Conductor $0.8 \mathrm{~mm}$ in diameter, $\mathrm{r}=1.4$. This is the case that we thought applied to magnets $1,2 \mathrm{~A}$ and $2 \mathrm{~B}$. It did not apply.

Case 1: This is the SSC Inner Conductor $1.32 \mathrm{~mm}$ in diameter, $\mathrm{r}=1.4$. This case applied in Magnets 1,2A and 2B. This case will not apply magnets that are refurbished because the bare conductor will be clad (Case 2,3, and 4).

Case 2: This case is the wire used in Case 1 plus two conductors that are 0.95 by $1.60 \mathrm{~mm}, \mathrm{r}=4.0$. This case applied inside and outside of the cold mass in Magnets 2A and 2B. The case will apply outside for the refurbished magnets as well.

Case 3: This case is the wire in Case 1 plus the $3.18 \mathrm{~mm}$ copper pin of the feedthrough. This case applies for both the old and the refurbished magnets.

Case 4: This case is the wires for case 2 that is clad with copper to form a conductor that has a cross-section that is $4.17 \mathrm{~mm}$ by $4.76 \mathrm{~mm}$. This case will apply inside the cold mass for all of the refurbished magnets.

Table 2. Lead Section Cross-section Area, Lead Current Density, Lead Copper to Superconductor Ratio r, Minimum Propagation Zone Length, and Quench Initiation Energy at a Current of 275 A

\begin{tabular}{|c|c|c|c|c|c|}
\hline CASE & $\begin{array}{c}\mathbf{A c} \\
\left(\mathbf{m m}^{\mathbf{2}}\right)\end{array}$ & $\begin{array}{c}\mathbf{J}_{\mathbf{M}} \\
\left(\mathbf{A ~ m}^{-2}\right)\end{array}$ & $\mathbf{r}$ & $\begin{array}{c}\text { MPZ length } \\
(\mathbf{m m})\end{array}$ & $\begin{array}{c}\text { QE } \\
(\mathbf{m J})\end{array}$ \\
\hline 0 & 0.502 & $5.50 \times 10^{8}$ & 1.40 & $\sim 3.3$ & 0.092 \\
\hline 1 & 1.368 & $2.02 \times 10^{8}$ & 1.40 & $\sim 9.2$ & 0.251 \\
\hline 2 & 4.338 & $6.34 \times 10^{7}$ & 3.74 & $\sim 46$ & 2.82 \\
\hline 3 & 7.917 & $3.47 \times 10^{7}$ & 13.9 & $\sim 160$ & 14.7 \\
\hline 4 & 19.706 & $1.39 \times 10^{7}$ & 33.8 & $\sim 420$ & 89.4 \\
\hline
\end{tabular}

The length of the adiabatic minimum propagation zone (with no transverse heat transfer) must be considered an approximation. Heat transfer in the transverse direction will lengthen the MPZ length. The effect of transverse heat transfer on the five cases will be discussed later. Inside of the helium vessel, transverse heat transfer to the helium will come into play. In the vacuum space transverse heat transfer plays no role. In the spreader transverse heat transfer will be used to cool the conductor that is firmly clamped and glued into the spreader. It is important to note that the MPZ is short for the single strands of SSC inner conductor. In both cases the MPZ length is less than a centimeter. This means that if the 1-centimeter of conductor turns normal, the quench will propagate. The energy needed to initiate a quench in the SSC inner conductor is quite low from 0.09 to $0.25 \mathrm{~mJ}$. A quench energy of $0.25 \mathrm{~mJ}$ is equivalent to the kinetic energy of a pin with a mass of 0.1 grams falling a distance of $0.25 \mathrm{~m}$. 


\section{Adiabatic Burn-out Time and Solder Melt time for Various Leads}

The equation for calculating the time that a lead will burn out is exactly the same equation that is used to calculate the hot-spot temperature during a quench. The time for a conductor to melt is of the properties of the conductor and the current density.

The limit for a burn out for the a conductor (conventional or superconducting) is derived from the following equation [16];

$$
\frac{\delta F}{\delta T}=j^{2}+\frac{1}{\rho} \frac{\delta}{\delta x}\left[\alpha \rho \frac{\delta F}{\delta x}\right]
$$

where $\mathrm{F}$ is defined as follows

$$
F(T)=\int_{0}^{T} \frac{C}{\rho} d T
$$

$-8 \mathrm{a}-$

where $\mathrm{C}$ is the volume specific heat and $\rho$ is the metal resistivity. $\alpha$ the thermal diffusivity is;

$$
\alpha=\frac{k}{C}
$$

Equation 2 is non-linear and hence it is difficult to solve in a meaningful way. There are three distinct regions. The first region is a region where the thermal diffusivity is low. When the thermally diffusivity is neglected, equation 2 takes the following form;

$$
\frac{\delta F}{d t}=j^{2}
$$

This equation can be used to calculate the burnout condition for a lead. It application has been used for superconducting magnets since the early 1970's [17], [18]. Redefining this equation 9 allows one to define the melt time $t_{\text {melt }}$, if one knows the melt temperature $\mathrm{T}_{\text {melt }}$.

$$
F^{*}(T)=\int_{0}^{T_{\text {melt }}} \frac{C(T)}{\rho(T)} d T=\frac{r+1}{r} \int_{0}^{t_{\text {melt }}} j^{2} d t
$$

If one assumes that the current density is a constant value $\mathrm{J}_{\mathrm{M}}$, one can derive the following equation for the burnout time for the lead;

$$
t_{\text {melt }}=\frac{F^{*}\left(T_{\text {melt }}\right)}{J_{M}^{2}} \frac{r}{r+1}
$$

Figure 7 shows $\mathrm{F}^{*}(\mathrm{~T})$ as a function of temperature $\mathrm{T}$ and the matrix material RRR. Figure 7 shows this for both matrix and aluminum matrix conductors. The lower values of $\mathrm{F}^{*}(\mathrm{~T})$ for aluminum conductors reflect the lower values of volume specific heat and higher resistivity for the matrix for a given RRR. 


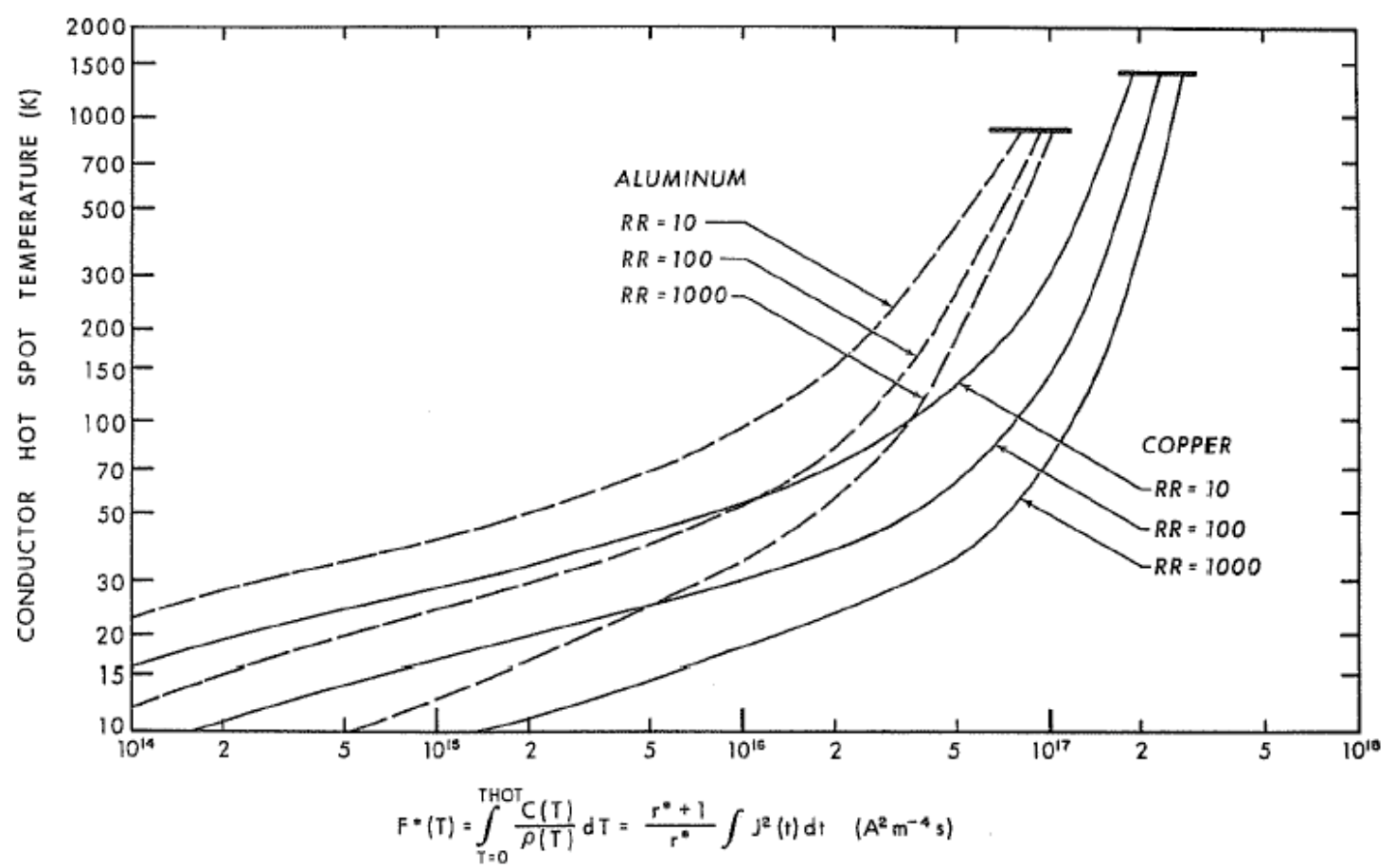

XBL 774-8481

Figure 7. Hot Spot Temperature $T_{M}$ versus $F^{*}(T)$ for Copper and Aluminum with Various RRR Values

Since all of the leads are made with a copper matrix. The melt temperature for the matrix material is $1350 \mathrm{~K}$. The melt temperature for the niobium-titanium is much higher. However, when the copper melts, the current is transferred to the niobiumtitanium, which has a low value of $\mathrm{F}^{*}$ for a given temperature. The niobium-titanium will melt quickly once the copper is melted. The melting point of the solder is $570 \mathrm{~K}$. For RRR $=100$ copper, $\mathrm{F}^{*}$ for the melting point of copper is $2.2 \times 10^{17} \mathrm{~A}^{2} \mathrm{~m}^{-4} \mathrm{~s}$. For $\mathrm{RRR}=100$ copper, the $\mathrm{F}^{*}$ for the melting of the solder is $1.7 \times 10^{17} \mathrm{~A}^{2} \mathrm{~m}^{-4} \mathrm{~s}$. Table 3 shows the value of $\mathrm{J}_{\mathrm{M}}, \mathrm{r} /(\mathrm{r}+1)$, the melt time for the copper, and melt time for the solder.

Table 3. Lead Section Cross-section Area, Lead Current Density, r/(r+1),

Adiabatic Copper Melt time, and the Adiabatic Melt Time for the Soft Solder at a Current of 275 A

\begin{tabular}{|c|c|c|c|c|c|}
\hline CASE & $\begin{array}{c}\mathbf{A c} \\
\left(\mathbf{m m}^{\mathbf{2}}\right)\end{array}$ & $\begin{array}{c}\mathbf{J}_{\mathbf{M}} \\
\left(\mathbf{A ~ m}^{-2}\right)\end{array}$ & $\mathbf{r} /(\mathbf{r}+\mathbf{1})$ & $\begin{array}{c}\text { Cu Melt Time } \\
(\mathbf{s})\end{array}$ & $\begin{array}{c}\text { Solder Melt Time } \\
(\mathbf{s})\end{array}$ \\
\hline 0 & 0.502 & $5.50 \times 10^{8}$ & 0.583 & $\sim 0.58$ & $\sim 0.45$ \\
\hline 1 & 1.368 & $2.02 \times 10^{8}$ & 0.583 & $\sim 4.4$ & $\sim 3.4$ \\
\hline 2 & 4.338 & $6.34 \times 10^{7}$ & 0.789 & $\sim 43$ & $\sim 33$ \\
\hline 3 & 7.917 & $3.47 \times 10^{7}$ & 0.932 & $\sim 170$ & $\sim 850$ \\
\hline 4 & 19.706 & $1.39 \times 10^{7}$ & 0.971 & $\sim 1110$ & \\
\hline
\end{tabular}


From Table 3 , it is clear that time to melt the copper is about 30 percent longer than the time that it takes to melt the solder in contact with the copper despite the fact that the melting temperature of copper is over 2.3 times the melting point of solder. The reason for this is that $\mathrm{C} / \rho$ goes down as the temperature increases.

The melt times given in Table 3 apply for RRR = 100 copper with no transverse heat transfer from the melting section. At the hot spot, the value of $\mathrm{dT} / \mathrm{dx}$ approaches zero. The transverse heat transfer is not zero, so transverse heat transfer increases the melt time. Another factor is the copper RRR. The RRR of copper in the superconductor used in the magnet is 70. The RRR of the copper in the SSC inner conductor is unknown, but it is probably of the order of 100. The RRR of the copper pins in the feed-through is unknown as is the RRR of the cladding copper. Finally, the melt times at $258 \mathrm{~A}$ is longer than the melt times for $275 \mathrm{~A}$. From Equation 11, the melt time for a lead carrying $258 \mathrm{~A}$ is about 14 percent longer than it is for $275 \mathrm{~A}$. For all of the reasons given above, the calculated melt times shown in Table 3 must be regarded as approximate.

It is interesting to note that there was no melting of the solder in the feed-through for the lead that melted. If one looks at Table 3, the explanation for this is clear. One can see in Table 3 that the melt time for the SSC inner wire (Case 1) is much shorter than the melt time for the solder in the feed-through (see Case 3). The normal region in the SSC inner wire propagates rapidly to the cladding conductor (Case 2) and the feed-through copper (Case 3). In both cases, the melt time for the SSC inner copper is a lot shorter than the time to melt the solder. The quench continues to propagate in the clad section

and in the feed-through, but the rate of propagation is much slower. Quench propagation along the wire will be discussed later in this report. Another factor that should be considered is the effect of transverse heat transfer within the helium vessel. Transverse heat transfer and cryogenic stability will be discussed in the next three sections.

\section{The effect of Transverse Heat Transfer on MPZ Length}

In order to see what the effect of transverse heat transfer one must go back to Equation 2 and add term for the transverse heat transfer as is shown below;

$$
L_{M P Z}=\left[\frac{2 k\left(T_{c}-T_{o}\right)}{J_{c}^{2} \rho-Q_{T}}\right]^{0.5}
$$

where $Q_{T}$ is the transverse heat transfer. As $Q_{T}$ approaches $j^{2} \rho$, the minimum propagation length $\mathrm{L}_{\mathrm{MPZ}}$ approaches infinity. This means that if the conductor is cryogenically stable the quench wont propagate because the MPZ length is infinite.

When one looks at effect of small amounts of transverse heat transfer the effect is also clear. When $\mathrm{Q}_{\mathrm{T}}<\mathrm{I}^{2} \mathrm{R}$, the following expression can be derived for $\mathrm{L}_{\mathrm{MPZ}}$;

$$
L_{M P Z}=\left[\frac{L_{O}\left(T_{c}^{2}-T_{o}^{2}\right)}{\left(J_{M} \rho_{M}\right)^{2}}\left(\frac{r}{r+1}\right)^{3}\right]^{0.5}\left[\frac{1}{I^{2} R-Q_{T}}\right]^{0.5} \text {, when } \mathrm{Q}_{\mathrm{T}}<\mathrm{I}^{2} \mathrm{R} \text {. }
$$

From Equation 13 one sees that if $\mathrm{Q}_{\mathrm{T}}$ is half of $\mathrm{I}^{2} \mathrm{R}, \mathrm{L}_{\mathrm{MPZ}}$ increases just over forty percent. If $\mathrm{Q}_{\mathrm{T}}$ is ten percent of $\mathrm{I}^{2} \mathrm{R}, \mathrm{L}_{\mathrm{MPZ}}$ increases about five percent. 


\section{The Transverse Heat Transfer Coefficient needed for Cryogenic Stability}

Depending on the transverse heat exchange, a conductor can be cryogenically stable or unstable. The other criterion is that the temperature of the conductor must be less than the critical temperature $T_{c}$, in order for the normal region to shrink. The concept of cryogenic stability was dates from 1965 [19]. The topic of cryogenic stability is well covered by Wilson [20] and for some types of magnets by Green [21].

The concept of cryogenic stability is very simple in that all that is required for cryogenic stability is that the ability to transfer heat from the conductor to the helium be greater than heat generation within the conductor, and the conductor temperature must be less that the superconductor critical temperature $\mathrm{T}_{\mathrm{c}}$. Cryogenic stability can be stated using the following expression;

$$
\alpha=\frac{h_{c} L P_{w}\left(T_{c}-T_{o}\right)}{\frac{i^{2} \rho_{M} L}{A_{c}}\left(\frac{r+1}{r}\right)}
$$

where $\alpha$ is the stability factor; $\mathrm{L}$ the length of the normal zone; $\mathrm{P}_{\mathrm{w}}$ is the wetted perimeter of the conductor; $h_{c}$ is the conductor surface convection heat transfer coefficient; $T_{c}$ is the critical temperature; $T_{o}$ is the operating temperature; $I$ is the operating current; $\rho_{M}$ is the matrix material resistivity; $\mathrm{A}_{\mathrm{c}}$ is the conductor cross-section area; and $\mathrm{r}$ is the copper to superconductor ratio for the conductor. For cryogenic stability $\alpha$ must be greater than 1 . The conductor is unstable when $\alpha$ is less than 1. At $\alpha$ equal 1 , the conductor is considered to be stable, but borders on being unstable. (In this case the MPZ length is quite long. The ramifications of this are discussed by Wilson [20].

The stability equation given above can be normalized using $\mathrm{J}_{\mathrm{M}}$ and by dividing out the terms. The stability equation takes the following form;

$$
\alpha=\frac{h_{c} P_{w}\left(T_{c}-T_{o}\right)}{J_{M}^{2} \rho_{M} A_{c}}\left(\frac{r}{r+1}\right)
$$

The lower limit for heat transfer per unit area $h_{c} \Delta T$ for stability $(\alpha>1)$, given in ( $\left.\mathrm{W} \mathrm{m}^{-2}\right)$ can be estimated by using the following analytical expression;

$$
\left(\frac{Q}{A}\right)_{S}=h_{c} \Delta T \geq h_{c}\left(T_{c}-T_{o}\right)=\frac{J_{M}^{2} \rho_{M} A_{c}}{P_{w}}\left(\frac{r+1}{r}\right)
$$

For cryogenic stability heat transfer per unit area to the helium $h_{c} \Delta T$ must be greater than shown in Equation 16. In addition, the temperature of the conductor must be less than $T_{c}$. To reduce the $h_{c} \Delta T$, one must increase the wetted perimeter $P_{w}$ and decrease $J_{M}$ and $\rho_{M}$. Increasing the copper to superconductor ratio $r$ also helps reduce the heat transfer per unit area to the helium. For stability with convection heat transfer to the helium, the value of the heat transfer coefficient $h_{c}$ must be;

$$
h_{c} \geq \frac{J_{M}^{2} \rho_{M} A_{c}}{P_{w}\left(T_{c}-T_{o}\right)}\left(\frac{r+1}{r}\right)
$$


The leads inside the cold mass helium tank that connect the feed-through to the magnet and its quench protection diodes operate in either liquid helium or helium gas, depending on the cryostat liquid level. The heat transfer from the leads to the helium must be calculated for both cases. Equation 16 is the stability equation that should be used when the leads are in liquid helium. Equation 17 is the stability equation that should be used when cryostat liquid level is low, and the leads are in helium gas.

\section{a) Boiling Heat Transfer to Liquid Helium from the Lead}

Heat transfer from the conductor surface to helium gas is through either nucleate boiling or film boiling. The maximum nucleate boiling heat flux per unit area $(\mathrm{Q} / \mathrm{A})_{\mathrm{np}}$ and the temperature drop from the boiling surface $(\Delta \mathrm{T})_{\mathrm{np}}$ to the bath can be estimated by using the following analytical expressions [22];

$$
\left[\frac{Q}{A}\right]_{n p}=0.016 h_{f g} \rho_{v}^{0.5}\left[\sigma g\left(\rho_{l}-\rho_{v}\right]^{0.25},\right.
$$

and

$$
\Delta T_{n p}=0.5\left[1-\frac{T_{s a t}}{T_{c r}}\right]^{b} T_{c r}
$$

where $h_{\mathrm{fg}}$ is the heat of vaporization of the fluid; $\sigma$ is the fluid surface tension; $\mathrm{g}$ is the acceleration of gravity; $\rho_{1}$ is the liquid density; and $\rho_{v}$ is the vapor density. The exponent coefficient $\mathrm{b}$ comes from the fitting equation. For a monatomic gas like helium $\mathrm{b}$ is $\sim 1$ and for a diatomic gas like hydrogen, nitrogen or oxygen $b$ is $\sim 1.5$. For helium, the measured maximum $(\mathrm{Q} / \mathrm{A})_{\mathrm{np}}$ is $\sim 8000 \mathrm{~W} \mathrm{~m}^{-2}$ and maximum $\Delta \mathrm{T}_{\mathrm{np}}$ is $\sim 0.8 \mathrm{~K}$.

The measured $(\mathrm{Q} / \mathrm{A})_{\mathrm{np}}$ is dependent on a number of factors including the orientation of the surface and the space between the conductor and an adjacent surface [23] to [25]. The peak nucleate boiling flux for helium is rarely $>8000 \mathrm{~W} \mathrm{~m}^{-2}$. This value applies for a surface in a large liquid volume facing upwards. If the surface is a vertical surface in a large bath $(\mathrm{Q} / \mathrm{A})_{\mathrm{np}}$ is reduced to $5000 \mathrm{~W} \mathrm{~m}^{-2}$. For a surface facing downward in a large bath $(\mathrm{Q} / \mathrm{A})_{\mathrm{np}}$ can be in the range from 1500 to $2000 \mathrm{~W} \mathrm{~m}^{-2}$. A surface that is close to another surface can have a $(\mathrm{Q} / \mathrm{A})_{\mathrm{np}}$ in the range of 2000 to $3000 \mathrm{~W} \mathrm{~m}^{-2}$ even when the surface is facing in a favorable direction. For a round or square conductor sitting in a helium bath, the design $(\mathrm{Q} / \mathrm{A})_{\mathrm{np}}$ should not be over $2000 \mathrm{~W} \mathrm{~m}^{-2}$ using nucleate boiling.

When the surface heat flux is too large for nucleate boiling, the surface is covered with a film of gas. This is called film boiling [25] [26]. The temperature of the surface can jump as much as $12 \mathrm{~K}$ in helium. If the break in nucleate boiling is at $2000 \mathrm{~W} \mathrm{~m}^{-2}$, the temperature drop is $\sim 3 \mathrm{~K}$. Film boiling cooling for the lead conductor is not an option because the temperature of the conductor is above the $T_{c}$ of the superconductor.

If the heat transfer per unit area from the lead surface is $>5000 \mathrm{~W} \mathrm{~m}^{-2}$, the lead is unlikely to be cryogenically stable. If the heat transfer per unit area from the lead surface is from 2000 to $5000 \mathrm{~W} \mathrm{~m}^{-2}$, the lead might be stable depending on lead orientation and closeness to other leads and surfaces. If the heat transfer per unit area for the lead surface is less than $2000 \mathrm{~W} \mathrm{~m}^{-2}$ the lead is cryogenically stable unless there is a temperature drop of more than $2.5 \mathrm{~K}$ in the insulation around the lead. 
The $(\mathrm{Q} / \mathrm{A})_{\mathrm{S}}$ is calculated for all of the cases using Equation 16. Table 4 shows which boiling regime the boiling heat transfer is in. Assuming a bath temperature of $4.2 \mathrm{~K}$, the estimated surface temperature of the conductor is given in Table 4. The approximate heat transfer coefficient for film boiling in helium is $\sim 670 \mathrm{~W} \mathrm{~m}^{-2} \mathrm{~K}^{-1}$ [27], [28].

Table 4. The Cross-section Area, Wetted Perimeter, r, Matrix Current Density, Heat Flow per Unit Area, Boiling Type and the Conductor Surface Temperature for Un-insulated Conductor at 275 A

\begin{tabular}{|c|c|c|c|c|c|c|c|}
\hline CASE & $\begin{array}{c}\mathbf{A c} \\
\left(\mathbf{m m}^{2}\right)\end{array}$ & $\begin{array}{c}\mathbf{P}_{\mathbf{W}} \\
(\mathbf{m m})\end{array}$ & $\begin{array}{c}\mathbf{( r + 1}) / \\
\mathbf{r}\end{array}$ & $\begin{array}{c}\mathbf{J}_{\mathbf{M}} \\
\left(\mathbf{A ~ m}^{-2}\right)\end{array}$ & $\begin{array}{c}\mathbf{Q} / \mathbf{A} \\
\left(\mathbf{W ~ m}^{-1}\right)\end{array}$ & Boiling Type & $\begin{array}{c}\text { Surface T } \\
(\mathbf{K})\end{array}$ \\
\hline 0 & 0.50 & 2.51 & 1.71 & $5.50 \times 10^{8}$ & 22700 & $\begin{array}{c}\text { Film } \\
\text { Unstable }\end{array}$ & 38.1 \\
\hline 1 & 1.37 & 4.15 & 1.71 & $2.02 \times 10^{8}$ & 5070 & $\begin{array}{c}\text { Transition } \\
\text { May be Stable }\end{array}$ & $\begin{array}{c}\sim 12 \mathrm{f} \\
\sim 4.9 \mathrm{n}\end{array}$ \\
\hline 3 & 4.34 & 7.00 & 1.27 & $6.34 \times 10^{7}$ & 690 & $\begin{array}{c}\text { Nucleate } \\
\text { Stable }\end{array}$ & 4.6 \\
\hline 4 & 19.71 & 17.86 & 1.03 & $1.39 \times 10^{7}$ & 33 & $\begin{array}{c}\text { Nucleate } \\
\text { Stable }\end{array}$ & 4.4 \\
\hline
\end{tabular}

Case 0 clearly isn't stable at $275 \mathrm{~A}$. In order for case 0 to be stable the lead current must be reduced to about $80 \mathrm{~A}$. It is unlikely that case 1 is stable for a long period of time. From the temperatures given in Table 4, case 1 is stable in nucleate boiling and unstable in film boiling. The transverse heat transfer from the conductor in case 1 has the effect of lengthening the MPZ length. It is quite possible that case 1 is stable in liquid helium, depending on lead orientation. Case 1 is clearly stable at a current of $\sim 175 \mathrm{~A}$. When the conductor is covered with liquid helium, cases 2, 3, and 4 are clearly stable.

\section{b) Natural Convection Heat Transfer to Helium Gas from the Lead}

Cooling with helium gas is a process of natural convection heat transfer to the gas. When natural convection cooling is compared to film boiling with large temperature differences, the natural convection heat transfer coefficient for hydrogen is ten percent of the film boiling heat transfer coefficient [27]. For helium the natural convection heat transfer coefficient is about two percent of the film boiling heat transfer coefficient [28]. The film boiling heat transfer coefficient for helium is twice that of hydrogen. At temperatures near the boiling point of helium, the heat transfer coefficient for helium may be quite a bit higher, because near its boiling point helium gas is more buoyant and the gas viscosity is lower [29].

One can calculate and estimated value for the heat transfer coefficient for free convection heat transfer using the following expression [30];

$$
h_{c}=\left[0.825+\frac{0.387 R a^{0.167}}{\left[1+\frac{0.492}{\operatorname{Pr}^{0.563}}\right]}\right]^{2} \frac{k}{D_{w}}
$$


where $\mathrm{k}$ is the thermal conductivity of the fluid, $\mathrm{D}_{\mathrm{w}}$ is the diameter of the conductor. The Rayleigh number $\mathrm{Ra}=\mathrm{Gr}$ Pr. Pr is the Prandtl number, and Gr is the Grashof number. The Prandtl number and the Grashof number are defined as follows;

$$
\begin{aligned}
& \operatorname{Pr}=\frac{\mu C_{p}}{k} \text { and } \\
& G r=\frac{g \beta\left(T_{c}-T_{o}\right) \rho_{v}^{2} D_{w}^{3}}{\mu^{2}}
\end{aligned}
$$

where $\mu$ is the fluid viscosity, $\mathrm{C}_{\mathrm{p}}$ is the fluid specific heat at constant pressure; $\mathrm{k}$ is the fluid thermal conductivity. The acceleration of gravity is $\mathrm{g}\left(\mathrm{g}=9.8 \mathrm{~m} \mathrm{~s}^{-2}\right) ; \beta$ is the buoyancy factor (for gasses $\beta=1 / T$ ); and $\rho_{v}$ is the fluid density. $T_{c}$ is the superconductor critical temperature and $\mathrm{T}_{\mathrm{o}}$ is the operating temperature (close to the helium bath temperature). The fluid properties are taken at $\mathrm{T}_{\mathrm{o}}$ because the insulation on the conductor is close to that temperature. For helium at $4.5 \mathrm{~K}$ the gas has the following properties:

$$
\begin{aligned}
& \mu=1.367 \times 10^{-6} \mathrm{~Pa} \mathrm{~s} \\
& \mathrm{C}_{\mathrm{p}}=11220 \mathrm{~J} \mathrm{~kg}^{-1} \mathrm{~K}^{-1} \\
& \mathrm{k}=0.101 \mathrm{~W} \mathrm{~m}^{-1} \mathrm{~K}^{-1} \\
& \rho_{\mathrm{v}}=22.12 \mathrm{~kg} \mathrm{~m}^{-3}
\end{aligned}
$$

As a result the calculated Dimensionless numbers are;

$$
\begin{aligned}
& \mathrm{Pr}=1.460, \\
& \mathrm{Gr}=8.53 \times 10^{14} \mathrm{D}_{\mathrm{w}}{ }^{3}, \text { and } \\
& \mathrm{Ra}=1.25 \times 10^{15} \mathrm{D}_{\mathrm{w}}{ }^{3} .
\end{aligned}
$$

Using the values given above and $D_{w}=\left(4 A_{C} / \pi\right)^{0.5}$, one can calculate the free convection heat transfer coefficient and the estimated wire surface temperature for the lead wires in helium gas at $4.2 \mathrm{~K}$ for the five cases. Table 5 shows the results of the calculation with no organic insulation on the wire.

Table 5. Lead Effective Diameter, Lead Current Density, heat Transfer Coefficient, and the Lead Surface Temperature at a Current of 275 A for Un-insulated Conductor

\begin{tabular}{|c|c|c|c|c|c|}
\hline CASE & $\begin{array}{c}\mathbf{D}_{\mathbf{w}} \\
(\mathbf{m m})\end{array}$ & $\begin{array}{c}\mathbf{J}_{\mathbf{M}} \\
\left(\mathbf{A ~ m}^{-2}\right)\end{array}$ & $\begin{array}{c}\mathbf{h}_{\mathbf{c}} \\
\left(\mathbf{W ~ m}^{-2} \mathbf{K}^{-\mathbf{1}}\right)\end{array}$ & $\begin{array}{c}\text { Surface T } \\
(\mathbf{K})\end{array}$ & Remarks \\
\hline 0 & 0.80 & $5.50 \times 10^{8}$ & 532 & $>47$ & Unstable \\
\hline 1 & 1.32 & $2.02 \times 10^{8}$ & 441 & $\sim 16$ & Unstable \\
\hline 2 & 2.35 & $6.34 \times 10^{7}$ & 369 & $\sim 6.1$ & Stable in 5.7 K gas \\
\hline 3 & 3.18 & $3.47 \times 10^{7}$ & 340 & $\sim 4.6$ & Stable in 7.2 K gas \\
\hline 4 & 5.01 & $1.39 \times 10^{7}$ & 303 & $\sim 4.3$ & Stable in 7.5 K gas \\
\hline
\end{tabular}


Table 5 shows that cases 2, 3 and 4 are stable in helium gas at $4.2 \mathrm{~K}$. Cases 0 and 1 are not stable because the wire temperature is above the superconductor $T_{c}$. Case 2 is stable when the wire is covered by liquid helium, but it is not stable when the wire is in gas at $\mathrm{T}>5.7 \mathrm{~K}$. The cold mass should be kept full of liquid helium, even though the wires for case 2 are well supported and are unlikely to move in the magnetic field. The next section shows the effect of the wire insulation on both boiling heat transfer to liquid helium and free convection heat transfer to the helium gas.

\section{The Effect of Lead Insulation on the Transverse Heat Transfer}

Insulation has two effects on the heat transfer from the conductor. Insulation increases the wire's wetted perimeter. The heat generated in the wire does not change when it is insulated, but the heat transfer to the fluid per unit area goes down. The down side of adding insulation to the wire is that it reduces the effective $U$ factor for heat transfer from the wire. As a result, the wire temperature usually goes up. If there is plenty of temperature margin in the superconductor, this may not a problem.

In order to calculate the $\mathrm{U}$ factor for the convective heat transfer plus the electrical insulation, one can use the following expression [31];

$$
\frac{1}{U}=\frac{1}{h_{c}}+\frac{t_{i}}{k_{i}}
$$

where $U$ is the heat exchange $U$ factor, $h_{c}$ is the heat transfer coefficient of the fluid; $t_{i}$ is the thickness of the insulation; and $\mathrm{k}_{\mathrm{i}}$ is the thermal conductivity of the insulation. Electrical insulation at $4.2 \mathrm{~K}$ has a low thermal conductivity (about $0.1 \mathrm{~W} \mathrm{~m}^{-1} \mathrm{~K}^{-1}$ ), but the thickness of the insulation $t_{i}$ is about $0.1 \mathrm{~mm}$. These values were used to calculate the $\mathrm{U}$ factor for the problem.

Calculation of an effective heat transfer for nucleate boiling is difficult because the temperature drop $\Delta \mathrm{T}_{\mathrm{b}}$ from the heated wall to the boiling fluid is proportional to the boiling heat flux $(\mathrm{Q} / \mathrm{A})_{\mathrm{b}}$ to the 2.5 power [32]. To calculate the boiling heat transfer coefficient $h_{b}$ (in place of $h_{c}$ in Equation 21), the author used the following expression;

$$
h_{b}=\frac{(Q / A)_{b}}{(\Delta T)_{b}}
$$

where the nucleate boiling temperature drop $\Delta \mathrm{T}_{\mathrm{b}}$ can be calculated using the following expression when the boiling heat flux $(\mathrm{Q} / \mathrm{A})_{\mathrm{b}},(\mathrm{Q} / \mathrm{A})_{\mathrm{np}}$, and $\Delta \mathrm{T}_{\mathrm{np}}$ are known;

$$
(\Delta T)_{b}=\left[\frac{(Q / A)_{b}}{(Q / A)_{n p}}\right]^{0.4}(\Delta T)_{n p},
$$

where $(\mathrm{Q} / \mathrm{A})_{\mathrm{np}}$ and $\Delta \mathrm{T}_{\mathrm{np}}$ are defined by Equations $18 \mathrm{a}$ and $18 \mathrm{~b} . \quad \mathrm{h}_{\mathrm{b}}$ for helium film boiling is $670 \mathrm{~W} \mathrm{~m}^{-2} \mathrm{~K}^{-1}$. For nucleate boiling $\mathrm{h}_{\mathrm{b}}$ can be as high as $10000 \mathrm{~W} \mathrm{~m}^{-2} \mathrm{~K}^{-1}$. The insulation can greatly reduce the $\mathrm{U}$ factor when boiling is involved in the process. 
Tables 6 and 7 show the performances of the five cases when the conductor is covered by electrical insulation $0.1 \mathrm{~mm}$ thick. From Tables 6 and 7, one can see that the transverse heat transfer per unit area is reduced because the insulation increases the wetted perimeter for heat transfer. Table 6 shows the boiling heat transfer coefficient $h_{b}$, the $\mathrm{U}$ factor and surface temperature $\mathrm{T}_{\mathrm{W}}$ for the cases. A temperature that is follow by an $\mathrm{n}$ indicates nucleate boiling. A temperature followed by an $\mathrm{f}$ indicates film boiling. Cases 2, 3 and 4 (the stable cases) in Table 6 are all in the nucleate boiling region. Cooling of conductor covered with insulation using cold helium gas is shown in Table 7 . The convective heat transfer coefficient $h_{c}$, the $U$ factor with insulation, and the conductor temperature are shown in Table 7.

Table 6. The Wetted Perimeter, Surface Heat flux, Boiling Temperature Drop, Boiling heat Transfer Coefficient $h_{b}$, $U$ Factor, and the Conductor Surface Temperature $T_{W}$ for the Five Cases at 275 A

\begin{tabular}{|c|c|c|c|c|c|c|c|}
\hline CASE & $\begin{array}{c}\mathbf{P}_{\mathbf{W}} \\
(\mathbf{m m})\end{array}$ & $\begin{array}{c}\mathbf{Q} / \mathbf{A} \\
\left(\mathbf{W} \mathbf{~ m}^{-2}\right)\end{array}$ & $\begin{array}{c}\Delta \mathbf{T}_{\mathbf{b}} \\
(\mathbf{K})\end{array}$ & $\begin{array}{c}\mathbf{h}_{\mathbf{b}} \\
\left(\mathbf{A ~ m}^{-2} \mathbf{K}^{-1}\right)\end{array}$ & $\begin{array}{c}\mathbf{U} \\
\left(\mathbf{W} \mathbf{~ m}^{-2} \mathbf{K}^{-1}\right)\end{array}$ & $\begin{array}{c}\text { Surface T } \\
(\mathbf{K})\end{array}$ & Remarks \\
\hline 0 & 3.14 & 18150 & $\sim 27$ & $670 \mathrm{f}$ & $400 \mathrm{f}$ & $>50 \mathrm{f}$ & Unstable \\
\hline 1 & 4.78 & 4400 & 0.63 & $\begin{array}{c}670 \mathrm{f} \\
7000 \mathrm{n}\end{array}$ & $\begin{array}{c}400 \mathrm{f} \\
875 \mathrm{n}\end{array}$ & $\begin{array}{c}\sim 15.2 \mathrm{f} \\
\sim 9.2 \mathrm{n}\end{array}$ & Unstable \\
\hline 2 & 7.80 & 620 & 0.28 & $2210 \mathrm{n}$ & $690 \mathrm{n}$ & $\sim 5.1 \mathrm{n}$ & Stable \\
\hline 4 & 01.61 & 141 & 0.16 & $880 \mathrm{n}$ & $470 \mathrm{n}$ & $\sim 4.5 \mathrm{n}$ & Stable \\
\hline
\end{tabular}

Table 7. The Wetted Perimeter, Surface Heat flux per unit Area, , Free Convection heat Transfer Coefficient $h_{b}$, U Factor, and the Conductor Surface Temperature $T_{W}$ for the Five Cases at 275 A

\begin{tabular}{|c|c|c|c|c|c|c|}
\hline CASE & $\begin{array}{c}\mathbf{P}_{\mathbf{W}} \\
(\mathbf{m m})\end{array}$ & $\begin{array}{c}\mathbf{Q} / \mathbf{A} \\
\left(\mathbf{W ~ m ~}^{-2}\right)\end{array}$ & $\begin{array}{c}\mathbf{H}_{\mathbf{c}} \\
\left(\mathbf{A ~ m}^{-2} \mathbf{K}^{-\mathbf{1}}\right)\end{array}$ & $\begin{array}{c}\mathbf{U} \\
\left(\mathbf{W ~ m}^{-\mathbf{2}} \mathbf{K}^{-\mathbf{1}}\right)\end{array}$ & $\begin{array}{c}\text { Surface T } \\
(\mathbf{K})\end{array}$ & Remarks \\
\hline 0 & 3.14 & 18150 & 497 & 332 & $>60$ & Unstable \\
\hline 1 & 4.78 & 4400 & 423 & 297 & $>20$ & Unstable \\
\hline 2 & 7.80 & 620 & 360 & 265 & $\sim 6.7$ & Stable in 5.1 K gas \\
\hline 3 & 01.61 & 141 & 334 & 250 & $\sim 4.8$ & Stable in 7 K gas \\
\hline 4 & 18.66 & 32 & 299 & 230 & $\sim 4.3$ & Stable in 7.5 K gas \\
\hline
\end{tabular}

With $0.1 \mathrm{~mm}$ of insulation on the wire, Cases 0 and 1 are always unstable. Cases 2 , 3 , and 4 are always stable in liquid helium. In helium gas, Case 2 is stable in gas up to a $\sim 5.1 \mathrm{~K}$. (Case 2 should be in liquid helium.) Cases 3 and 4 are always stable at any temperature in the helium gas at which the spectrometer solenoid can operate. 
It is worth talking about cooling outside of the cold mass helium vessel. There is no cooling except cooling that is by thermal conduction. The conductor in the feed-through is conductively cooled. The $1.32 \mathrm{~mm}$ diameter wire that comes through the feed-through is not cooled except at the ends. This wire is well supported and less than a MPZ length.

The lead wires that are in the spreader shown in Figure 6 have at least the same cross-section as case 2. There may well be more copper on those wires than is shown for Case 2. The lead wires are glued and clamped to the spreader plate, which are thermally connected to the helium tank. If the helium tank has any liquid in it, the tank should be colder than the gas that might collect at the top of the tank. Heat transfer from the wires to the tank is through an aluminum slab that is welded directly to the tank. Heat is conducted through insulation. The minimum perimeter for this connection is $\sim 2 \mathrm{~mm}$ wide. This is not the perfect situation from cryogenic stability standpoint. The wires are rigidly glued and physically clamped to the aluminum spreader plate. It would be better of the wires were cooled on both sides by two aluminum spreader plates. The field in the spreader plate is low. There is a very low probability of conductor motion in the wires attached to the spreader plate.

Table 8 shows the heat transfer perimeter $\mathrm{P}_{\mathrm{w}}$, the heat flow per unit area across the insulation, the $\mathrm{U}$ factor based on $0.1 \mathrm{~mm}$ of insulation and the temperature of the conductor should it turn fully normal. Table 8 applies for cases 2 and 4 with heat being transferred across one of the four surfaces (the largest of the four surfaces). If the lead conductor is cooled on two surfaces, the $\Delta \mathrm{T}$ is reduced by a factor of two.

Table 8. The Heat Transfer Perimeter, the Surface Heat flux per unit Area, , the U Factor, the $\Delta \mathrm{T}$ across the Insulation, and the Surface Temperature $\mathrm{T}_{\mathrm{W}}$ for Cases 2, 3 and 4 at $275 \mathrm{~A}$

\begin{tabular}{|c|c|c|c|c|c|c|}
\hline CASE & $\begin{array}{c}\mathbf{P}_{\mathbf{W}} \\
(\mathbf{m m})\end{array}$ & $\begin{array}{c}\mathbf{Q} / \mathbf{A} \\
\left(\mathbf{W} \mathbf{~ m}^{-2}\right)\end{array}$ & $\begin{array}{c}\mathbf{U} \\
\left(\mathbf{W ~ m}^{-2} \mathbf{K}^{-1}\right)\end{array}$ & $\begin{array}{c}\Delta \mathbf{T} \\
(\mathbf{K})\end{array}$ & $\begin{array}{c}\text { Surface T } \\
(\mathbf{K})\end{array}$ & Remarks \\
\hline 2 & 1.90 & 2500 & 1000 & $\sim 2.5$ & $\sim 6.7$ & Stable to $5.4 \mathrm{~K}$ \\
\hline 3 & 10.00 & 690 & 1000 & $\sim 0.7$ & $\sim 4.9$ & Stable to $7.2 \mathrm{~K}$ \\
\hline 4 & 4.76 & 125 & 1000 & $\sim 0.13$ & $\sim 4.33$ & Stable to $7.8 \mathrm{~K}$ \\
\hline
\end{tabular}

From Table 8 it is clear that case 2 is stable until the spreader temperature reaches $5.4 \mathrm{~K}$. If the insulation thickness were doubled, this case would be unstable. Case 3 is stable for an insulation thickness of $0.1 \mathrm{~mm}$ or $0.2 \mathrm{~mm}$. The insulation for case 3 is ceramic so its thermal conductivity should be larger. Case 4 is stable to any temperature the magnet can operate. This stability remains even if the insulation thickness is doubled. If the conductor in cases 2 and 4 is cooled from both sides, both of these cases are stable. It is clear the spreader insulation must be thin and cooling two sides of the conductor is better than cooling only one side.

The cold end of HTS leads is thermally tied to the helium tank. As a result, no heat conducted down the LTS superconducting lead from the $64 \mathrm{~K}$ (the maximum design upper end temperature for the HTS leads) gets into the spreader plate from the LTS leads cooled by the plate. When the HTS lead failed in magnet 2A, there was no evidence of over heating of any of the wires connected to the spreader plate. 


\section{Adiabatic Quench Propagation Velocity along the Leads}

The final design consideration is the quench propagation velocity should a normal region (larger than a MPZ length) develop in the lead. In a sense this is a measure of the lead's ability to take the quench into the magnet. The quench propagation velocity calculated for magnet quenches is the adiabatic quench propagation velocity, which ignores heat transfer in the transverse direction. Transverse heat transfer affects quench propagation in the same way that it affects the MPZ length.

The calculation of the normal region velocity along the wire uses the same equation as is used to calculate the burn out of a conductor. (See Equation 7, 8a and 8b.) Instead of taking the first region (used for the burn out calculations) we take the second region that is dominated by heat transfer. In this region the conductor is not superconducting and electrical resistivity $\rho$ is constant. As a result, the thermal conductivity is proportional to temperature. (See Equation 4 with $\rho$ a constant.) The specific heat is small and it is proportional to $\mathrm{T}^{\mathrm{N}}$, where $\mathrm{n}$ is between 2 and 3 . Within this region, Equation 7 takes the following form [18], [33];

$$
\frac{\delta F}{\delta T}=j^{2}+\frac{\delta}{\delta x}\left[\alpha \frac{\delta F}{\delta x}\right]
$$

where $\mathrm{F}$ and a are defined by Equations $8 \mathrm{a}$ and $8 \mathrm{~b}$; and $\mathrm{j}$ is the current density in the wire. Equation 24 takes the form that is similar to the wave equation. From this equation a quench velocity can be derived.

The velocity of normal region propagation can be found in equations 24 . The solution takes the following general form [34];

$$
v<j\left[\frac{\rho_{n} \alpha_{n c}}{h_{n c}-h_{n o}}\right]^{0.5},
$$

where $\rho_{\mathrm{n}}$ is the resistivity of the normal metal; $\alpha_{\mathrm{nc}}$ is the thermal diffusivity of the normal metal at the superconductor critical temperature. $\left(h_{n c}-h_{n o}\right)$ is the enthalpy change per unit volume from the operating temperature $T_{o}$ to $T_{c}$. The resistivity the thermal conductivity portion of $\alpha$ can be normalized by the factor $(r+1) / r$ and the Wiedeman and Franz equation can be used create an equation that takes the following form;

$$
v<j\left[\frac{L T_{c}}{C_{n c}\left(h_{n c}-h_{n o}\right)}\right]^{0.5} .
$$

From equation 26 it is clear that the normal metal thermal conductivity, normal metal electrical resistivity, and $\mathrm{r}$ have almost no effect on normal region propagation velocity. When LBL fit equation 26 to measured data from the late 1970's, the following expression was obtained;

$$
v \approx 0.6 j\left[\frac{L T_{c}}{C_{n c}\left(h_{n c}-h_{n o}\right.}\right]^{0.5} .
$$


Equation 27 is dependent only on the current density in the conductor cross-section $\mathrm{j}$ and the magnetic induction $\mathrm{B}$ the conductor sees. The dependence on matrix current density is about $\mathrm{j}^{1.5}$ at low current densities. At high current densities where transverse heat exchange can be neglected, the matrix current density dependence is more like $\mathrm{j}^{2}$ as observed by Scherer and Turowski [35]. At current densities in the range of the MICE magnets, the dependence is more like $\mathrm{j}^{1.65}$. This dependence can be used over arrange of current densities from $1 \times 10^{8}$ to $4 \times 10^{8} \mathrm{~A} \mathrm{~m}^{-2}$. The fitting equation derived from LBL and other measured data within a potted coil takes the following form [36];

$$
v \approx\left(5.7 \times 10^{-14}\right)[1+B]^{0.62} J_{M}^{1.65} .
$$

Equation 28 is dependent only on B and $\mathrm{J}_{\mathrm{M}}$. Equation 28 has also been used X. L Gou et al for the quench protection calculations on all of the MICE magnets [37], [38], and [39].

Table 9 shows the calculated adiabatic quench velocities for conductor cases 0 through 4. The magnetic field assumed was $0.5 \mathrm{~T}$. The values of $\mathrm{J}_{\mathrm{M}}$ are given in Table 9 . The last column in Table 9 is a remarks column that says whether or not the quench propagation will occur or not. In the cases that are cryogenically stable, the actual quench propagation velocities will be zero up to a certain liquid or gas temperature.

Table 9. Lead Section Cross-section Area, Lead Current Density, the adiabatic Quench Velocity, and the Estimated Quench Velocity at a Current of $275 \mathrm{~A}$ and a Magnetic Induction of $0.5 \mathrm{~T}$

\begin{tabular}{|c|c|c|c|c|c|}
\hline CASE & $\begin{array}{c}\text { Ac } \\
\left(\mathbf{m m}^{2}\right)\end{array}$ & $\begin{array}{c}\mathbf{J}_{\mathbf{M}} \\
\left(\mathbf{A ~ m}^{-2}\right)\end{array}$ & $\begin{array}{c}\text { Adiabatic V } \\
\left(\mathbf{m ~ s}^{-1}\right)\end{array}$ & $\begin{array}{c}\text { Estimated V } \\
\left(\mathbf{m ~ s}^{-1}\right)\end{array}$ & Remarks \\
\hline 0 & 0.502 & $5.50 \times 10^{8}$ & 19.4 & $\sim 18.7$ & Always Unstable \\
\hline 1 & 1.368 & $2.02 \times 10^{8}$ & 3.71 & $\begin{array}{c}\sim 3.34 \\
\text { in Gas }\end{array}$ & $\begin{array}{c}\text { Always Unstable } \\
-0-\end{array}$ \\
\hline 2 & 4.338 & $6.34 \times 10^{7}$ & 0.55 & $\begin{array}{c}\text { Stable to 5.1 K in Gas } \\
\text { Always Stable in Liquid }\end{array}$ \\
\hline 3 & 7.917 & $3.47 \times 10^{7}$ & 0.20 & $-0-$ & $\begin{array}{c}\text { Stable to 7 K in Gas } \\
\text { Always stable in Liquid }\end{array}$ \\
\hline 4 & 19.706 & $1.39 \times 10^{7}$ & 0.045 & $-0-$ & Always Stable \\
\hline
\end{tabular}

The adiabatic and real quench propagation velocities are different because there is transverse heat flow from the wire to the surrounding liquid or gas. If half of the heat produced is removed in the transverse direction, the velocity goes down by a factor of 1.4. If all of the heat can be removed by heat transfer in the transverse direction the real quench propagation velocity is zero and the MPZ length is infinite. Table 9 reflects the heat transfer shown in Tables 6,7 and 8. Cases 3 and 4 are stable at any temperature that the spectrometer solenoid can operate. Case 2 is stable to temperatures of $5.1 \mathrm{~K}$ to $6.7 \mathrm{~K}$ depending on the case. It appears that case 2 is more stable in the spreader section than it is in a tank with helium gas. Case 2 is always stable in liquid helium. This suggests that the tank should be kept full of liquid helium when the magnet is running. 


\section{Changes made on the Magnet Leads and their Effect on Stability}

When the magnet cold mass was opened up, a section of the cryostat wall was removed permitting one to uncover the quench by-pass resistors and the region next to the feed-throughs. This also provided an opportunity to look at the lead wiring from the magnet coils to the feed-throughs. Because the vendor had good access to the bottom of the feed-through, the wires could be connected to the feed-through in a different way, which eliminated the slack in the leads that permitted the bare $1.32 \mathrm{~mm}$ diameter lead near the feed through to move.

It was clear to the vendor that the wire the failed was a high current density lead that could be subject to motion due to magnetic forces on a much longer section of wire that was not properly supported. Cladding was added to the wire passing through the pin of the feed-through. The copper cladding was soldered to the feed-through pin wire right up to the feed-through pin on both sides. The copper cladding is installed around feedthrough wire and two pieces of standard wire (case 2). The clad section is case 4 in table 2 through 9 . The copper cladding was mechanically supported by wrapping the section with copper wire and solder. The mechanical support effectively increases the crosssection even more than is shown in case 4.

There was no section of bare wire between the feed-through pin and the clad wire. The feed-through pin makes the $1.32 \mathrm{~mm}$ diameter SSC inner wire stable (see case 3 in tables 2 through 9). The cladding provides extra stiffness and resistance to conductor motion in the magnetic field. The clad wire has added support to the magnet to resist conductor movement, thus preventing a normal region of any length from forming. Figure 8 shows the repaired feed-through with a pair of MICE conductors connected to the wire coming through the pin (case 2). About $50 \mathrm{~mm}$ below the pin the thicker clad section starts (case 4).

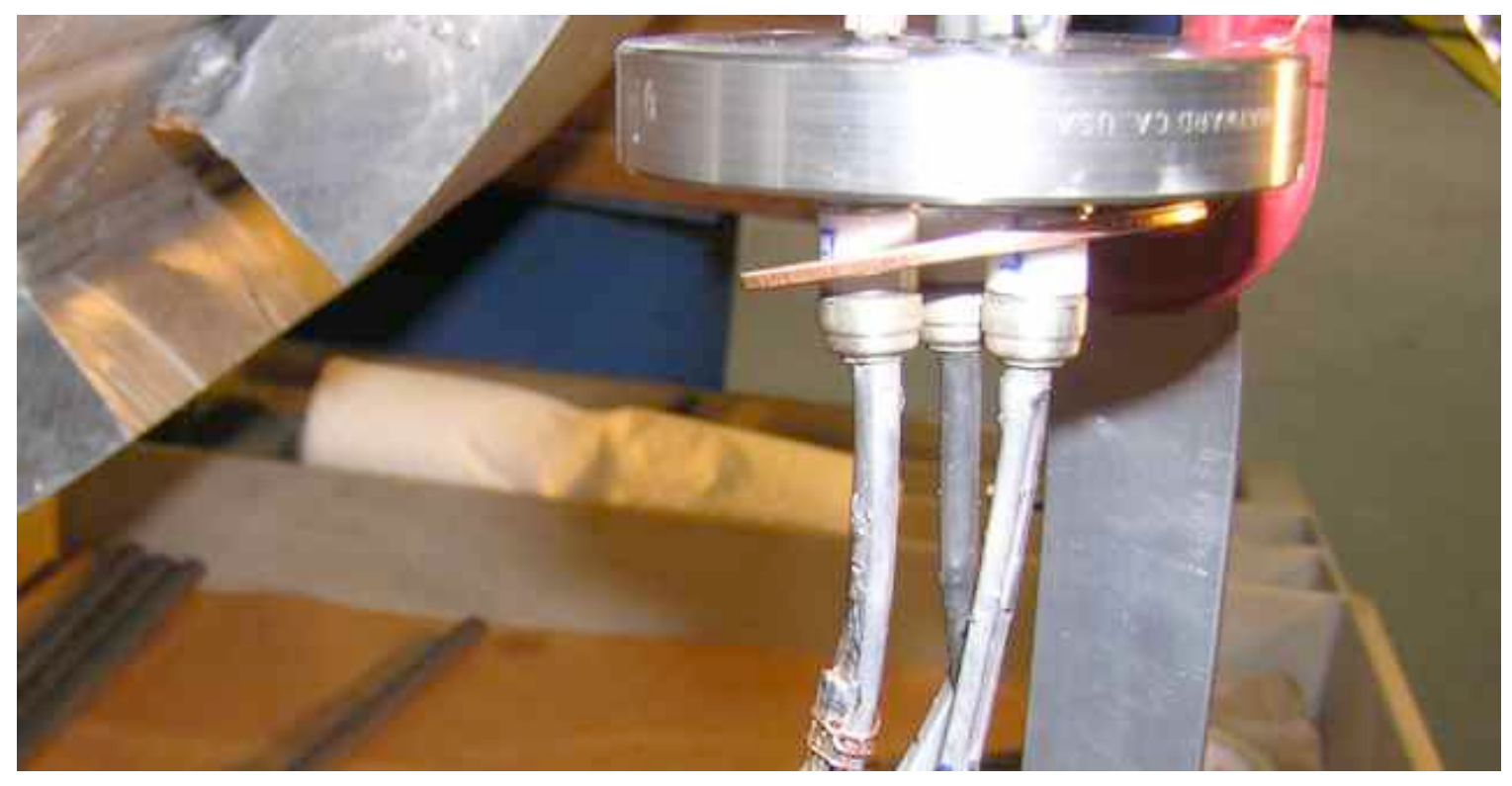

Figure 8. A Photo of the Repaired Conductor Section at location close to the Feed-through Pin 


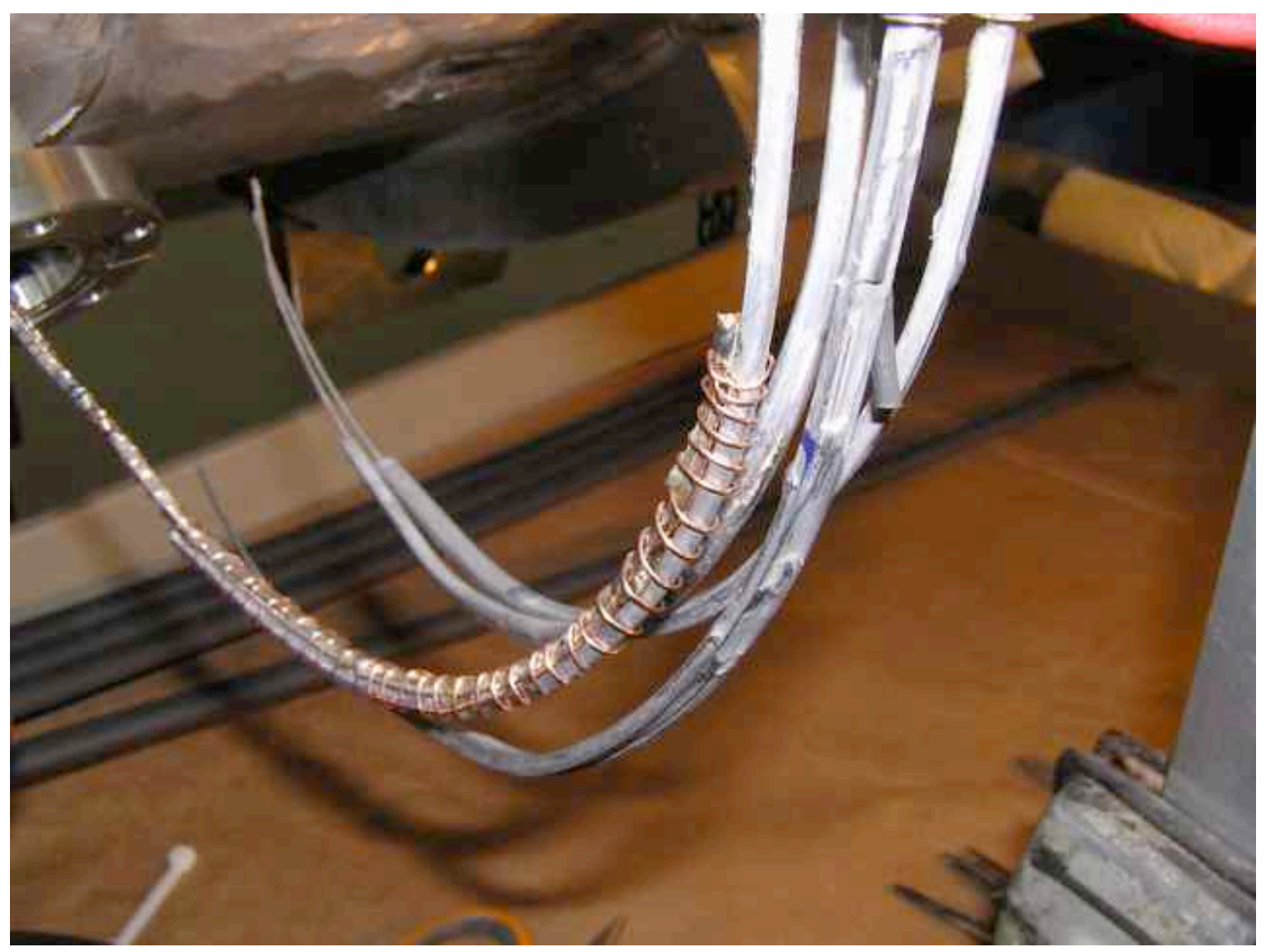

Figure 9. The Repaired Section showing the Clad Wire (case 4), which is soldered to the MICE Conductor Pair (case 2). (The clad section increases the stiffness of the lead going to the magnet.)

\section{Other Issues found when the Magnet was Disassembled}

When the cold mass for magnet two was disassembled, another problem was encountered. The G-10 insulation between the quench resistors protection resistors and the cold mass cover plate in the helium space was badly burned, where the insulation was next to six of the nine resistors. The overheated stainless resistors that were warped and discolored must have been quite hot. Figure 10 shows the burned insulation above five of the overheated resistors. The sixth (at the left end) warped downward so that it didn't touch the insulation. The other three resistors where there was no burning of the G-10 insulation appear that they had never carried enough current to overheat. The numbers that had been put on the three unburned resistors using a felt tip pen were still on the resistors. The six burned resistors had the numbers burned off of them.

Figure 11 shows the magnet quench protection resistors after they were installed into magnet two. If one looks at figure 11 , one see that there are nine 0.015 -ohm resistors and six pairs of back-to-back diodes. The magnet has three separate 300 circuits; a circuit for coil M1, a circuit for coil M2, and a circuit for the three-coil set (coils E1, Center, and E2). Circuits for coils E1 and E2 have a pair of back-to-back diodes and a 0.015-ohm resistor is series with the dipole. The three-coil set has four pairs of back-to-back diodes that are each in series with a $0.015-\mathrm{ohm}$ resistor. Coil E1 and E1 have one resistor. The center coil has a center tap and two resistors and two pairs of diodes across them. 


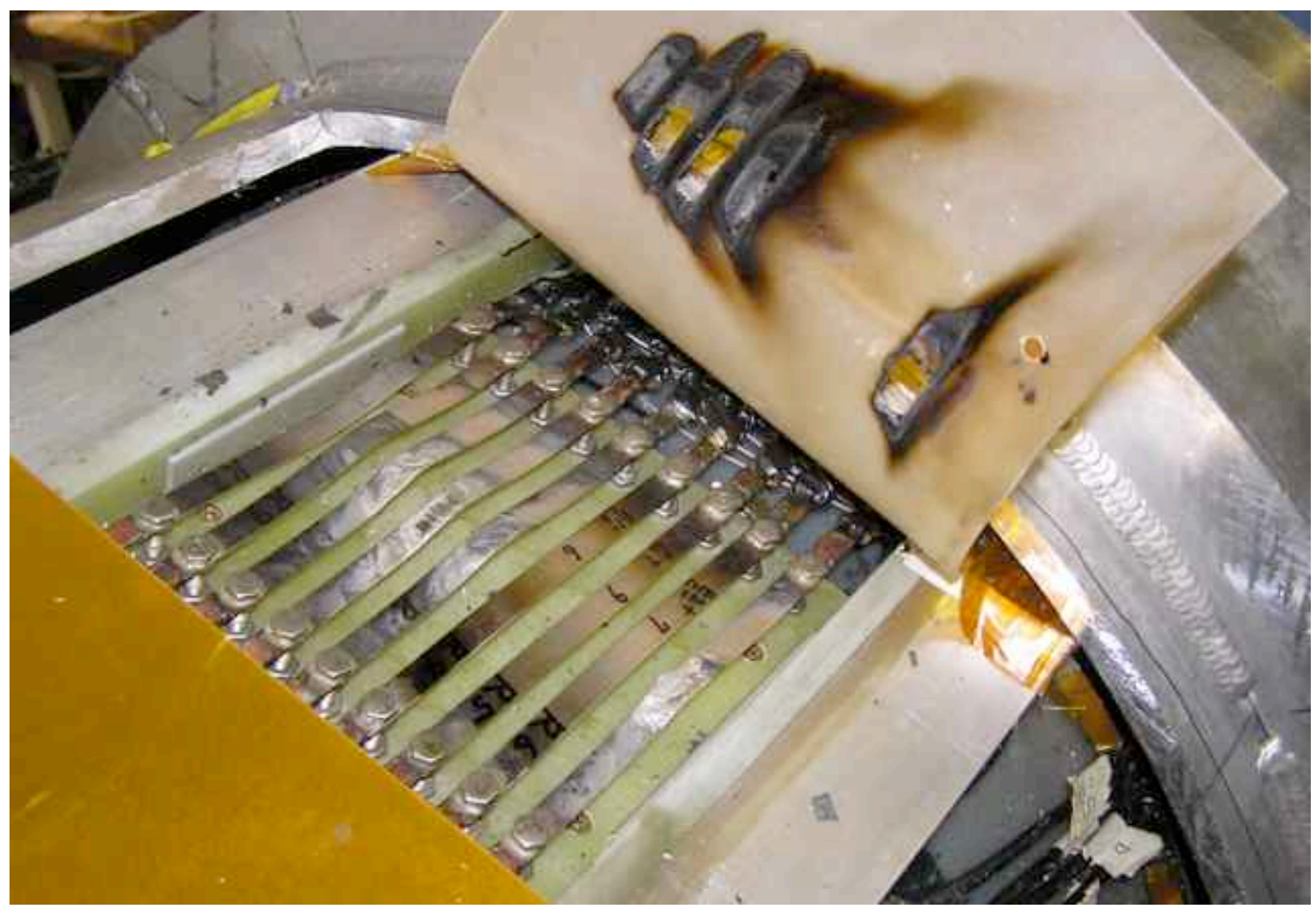

Figure 10. Burning of the G-10 Insulation between the Resistors and the Cold Mass Cover Plate in Magnet. (Note: Six of the nine resistors are warped and discolored due to resistor overheating.)

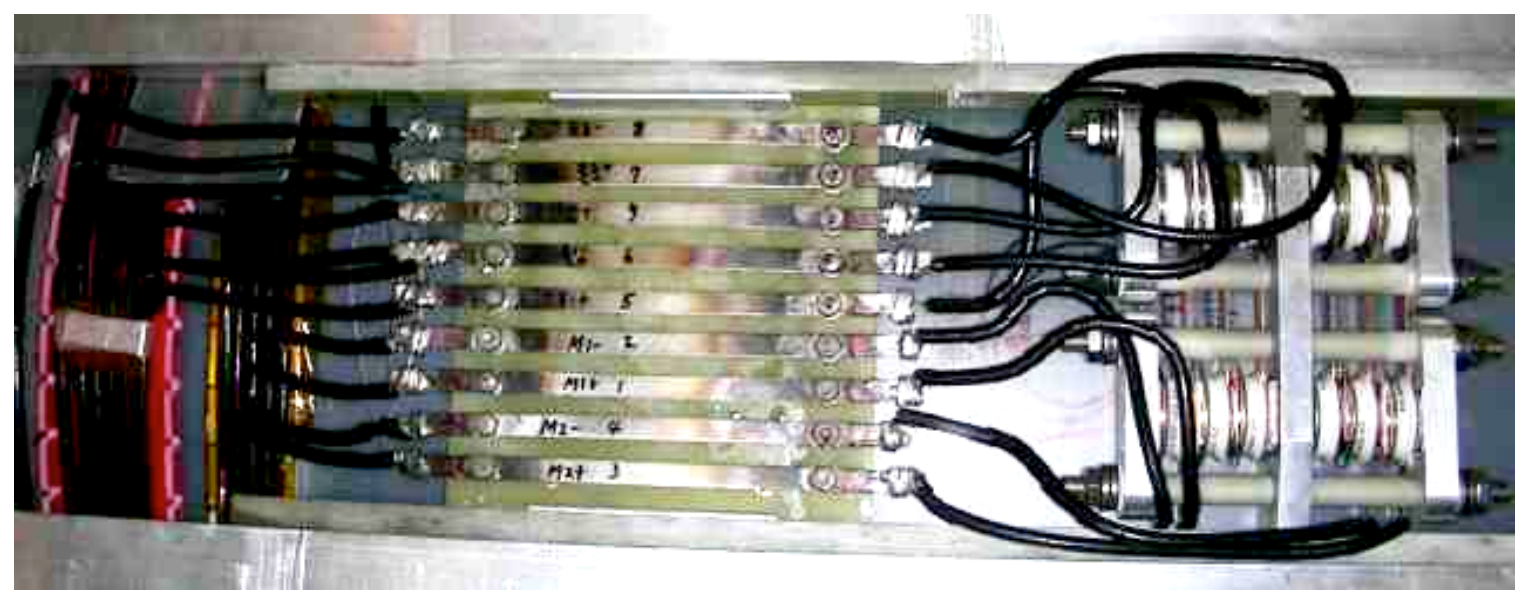

Figure 11. The Resistors and Diodes as Installed in Magnet 2 in 2007

The cables connecting the coils to the resistors and the resistors to the diodes are quite heavy. The burnout time for cables like these is quite long. During a quench there would be no overheating of these cables. It should be noted that the diodes are compressed in the frame. This means that the copper plate at end of the diodes is well compressed against the silicon wafer. If the copper is not pressed firmly onto the surface of the silicon, the silicon will spall from overheating. The current going through the diodes must be spread evenly across the silicon wafer surface. 
Why are there nine resistors when only six resistors are need for sub-dividing the voltages while protecting the magnet during a quench? This was a puzzle until the author realized that there are nine voltage taps going into the spectrometer solenoid. There are two voltage taps each for coils M1 and M2. There are five voltage taps across the three-coil set. There is one voltage tap at each end of the coil set, there are voltages taps between coil E1 and the center coil and between the center coil and coil E2. The center coil is sub-divided into two-parts, the ten inner layers and the ten outer layers, so the fifth voltage tap on the three-coil set is the center tap. The author assumed that the extra resistors were for preventing current surges. Because the voltage taps and other wires are routed through a cold mass cryostat vent pipe, it is difficult to install the surge resistors in series with the voltage tap wires. This is what the author thought the vendor was trying to do, but author turned out to be wrong.

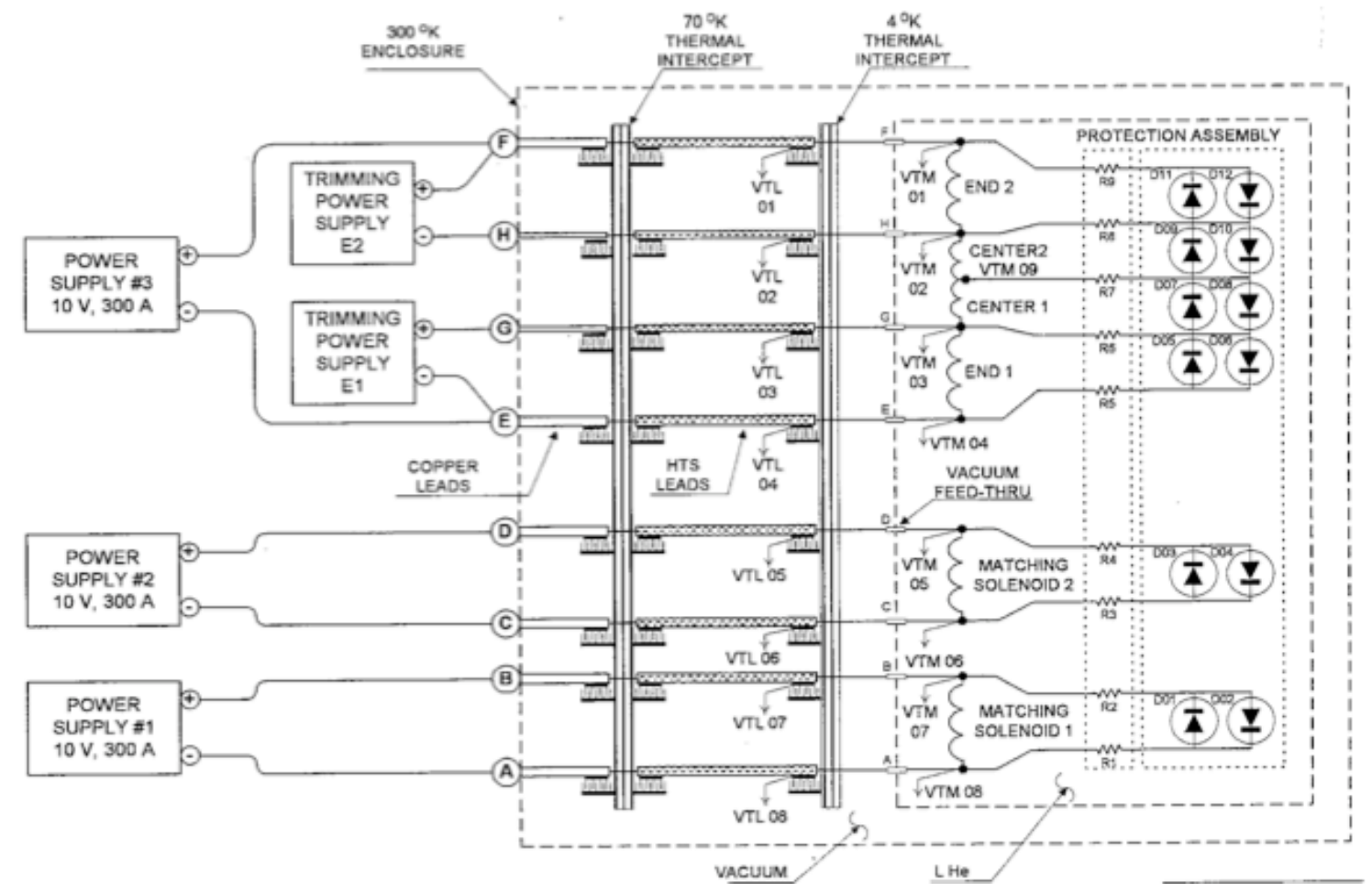

Figure 12. The Circuit Diagram for both Spectrometer Solenoids (During the test that burned out the lead on the M2 coil a single 300 A power supply was connected across the magnet from Lead A to Lead F. There are jumper cables between leads $\mathrm{B}$ and $\mathrm{C}$ and between lead $\mathrm{D}$ and $\mathrm{E}$. There were no trimming power supplies between leads E and G and between leads H and F. Surge resistors are not shown.)

Figure 12 shows the circuit diagram for the MICE spectrometer solenoid. Figure 12 shows location of the voltage taps on the coil. Eight taps are on the coil ends. The ninth tap is on the long coil center tap. If there are resistors to control the current surge due to voltage they are not shown in Figure 12. Figure 12 does not show the location of the voltage taps at both ends of the HTS leads. These are shown in Figure 13 as voltage taps VTL-01 through VTL-16. There are eight taps at the $4 \mathrm{~K}$ ends of the HTS leads and eight taps at $60 \mathrm{~K}$ ends of the HTS leads. In addition the voltage can be measured at the top of the $300 \mathrm{~K}$ leads. The taps shown in Figure 12 are VTM-01 through VTM-09. 


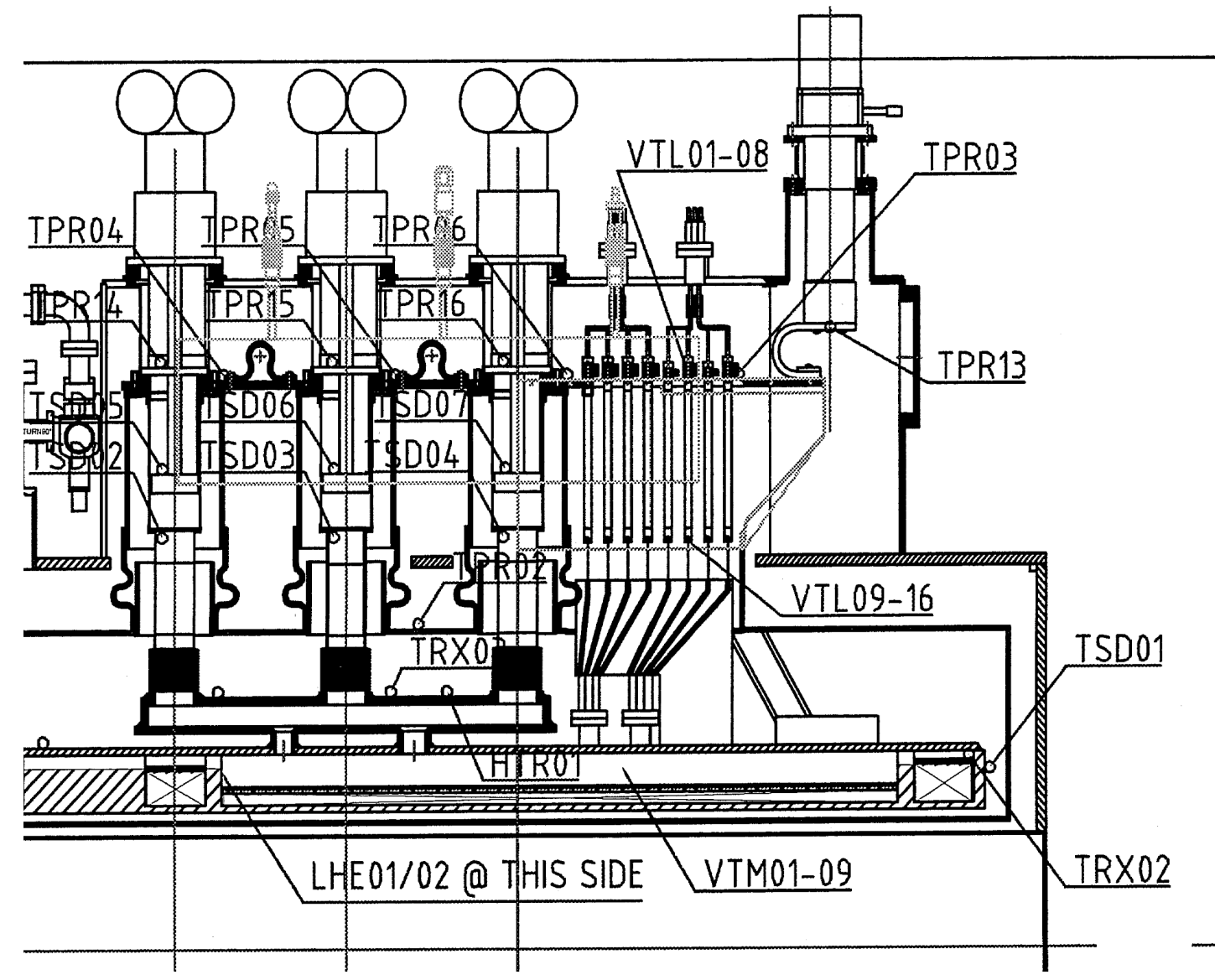

Figure 13. The Location of the Voltage Taps and other Instrumentation in Magnet 2B. (VTM01 to VTM09 are in the voltage taps in the magnet cryostat (see Figure 12). VTL01 to VT08 are voltage taps located at the top of the HTS leads. VTL09 to VTL16 are voltage taps at the bottom of the HTS leads.

The resistors that overheated are the quench protection resistors that are connected to leads A, B, C, D, E, and H. It is clear that the overheating of the resistors and the burning of the insulation was not caused by a normal mode of magnet quenching. During a normal magnet quench, all of the quench protection resistors shown in Figures 11 and 12 are involved in the quench process. These resistors have enough mass, so that there is no overheating by the current that flows through them during a quench [39]. The resistor mass needed to protect the resistors during a quench is $\sim 2 \mathrm{~kg}$ per ohm of resistance. The decay time constant through the resistors during a magnet quench is from 4 to 6 seconds. One can look at the quench protection equations [18], [33] and see that there is enough resistor mass to keep the resistor from getting too warm $(<300 \mathrm{~K}$ at $275 \mathrm{~A})$. The mass of the 0.015 -ohm resistors is more than 40 grams per resistor.

The cause of the six quench protection resistors overheating is one or both of two possible causes. They are: 1) When a lead is burned out the magnet current flows through the six resistors and the diodes connected to them. Current doesn't flow through resistors R6 through R8. 2) When the power supply has been left on after the magnet quenches the current flows through the same six resistors. Both of these reasons are plausible for magnet 2 . Only the second reason is applies for magnet 1 (no lead failure). 


\section{a) Resistor Overheating due to a Magnet Lead Failure}

Conversations Vladimir Kashikhin of Fermilab caused me to look carefully at this scenario. This scenario can occur when an LTS lead burns out (for example when the M2 lead failed in the magnet 2B test), when a HTS lead burns out (the lead H failure during the magnet 2A test), or when an external lead is disconnected while the magnet is being powered. Since the magnet was tested with all five coils in series, a lead failure can lead to excessive heating in all six resistors and the diode packs that are in series with the resistors. The temperatures reached in the resistors is dependent on 1) the magnet current during the lead failure, 2) the time it takes for the lead failure to induce a magnet quench, and 3) the rate of heat transfer from the resistors while they are at elevated temperatures. During the lead failures in magnet 2, the currents were within 87 percent of the maximum design current for the spectrometer solenoid.

When the M2 lead failed during the test of all five coils in series, the current flow in the spectrometer solenoid changed from the configuration shown in Figure 12 to the configuration shown in Figure 14. The current in the spectrometer solenoid changed from a single series circuit to three separate circuits that are coupled to each other. Each coil circuit is closely coupled to the mandrel that the coil circuit is wound upon. Each circuit has its own L/R current decay constant. The $\mathrm{L} / \mathrm{R}$ time constants for the three circuits shown in Figure 14 are given in Table 10. The current decay in the circuit induces current flow in the mandrel, which will eventually causes the coil to quench through quench-back [33], [42], [43], and [44]. The process of quenching the three-coil set may be speeded up by the heating produced in the resistors, which are next to the aluminum banding of the center coil within the helium space.

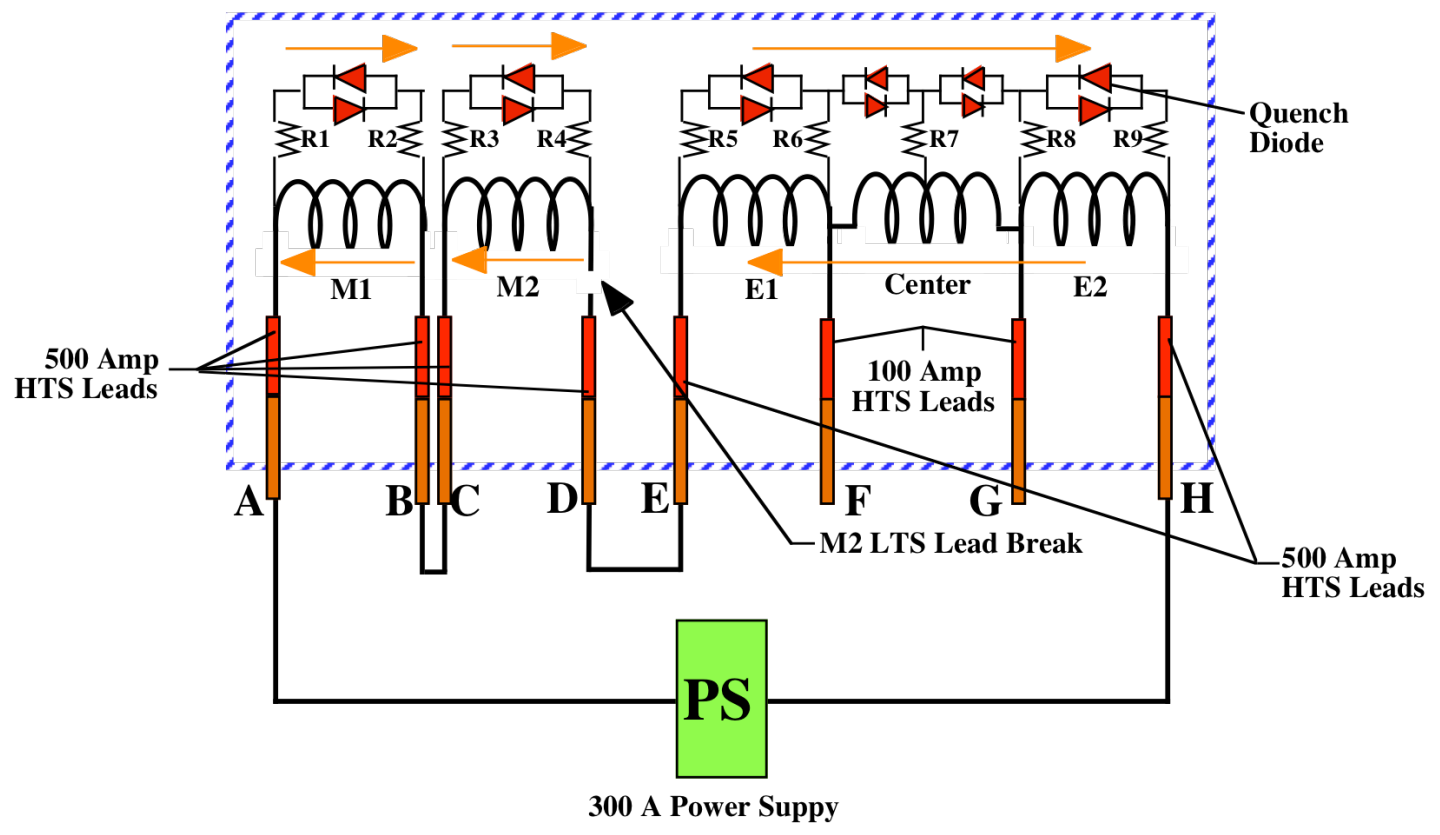

Figure 14. The Reconfiguration of the Currents in the Spectrometer Solenoid with all Five Coils connected in Series after a Lead Fails (The M2 lead failure in the magnet 2B test is shown in this figure. Note: Resistors R6, R7, and R8 are not carrying current, so they do not part of the L/R time constant for the system. This current configuration also applies when the HTS lead failed during the magnet 2A test.) 
One can estimate the time needed for the magnet to quench once a lead has been burned-out. A lead failure causes the diodes to fire, to that spectrometer magnet is divided into three separate circuits. Once diodes have fired and the current must be redistributed between the three circuits. The time constant for current redistribution between the coils is shorter that the decay time constant for the magnet as a whole. One can simplify the problem based on the assumption of good coupling between the coil and the mandrel. The estimated coil to mandrel coupling coefficient is $\sim 0.92$. If one takes into account the coupling coefficient, quench-back time will go up $\sim 9$ percent.

The resistance needed to induce quench-back $\mathrm{R}_{\mathrm{QB}}$ can be estimated using the following expression [33];

$$
R_{Q B}=\left(\frac{1}{\delta}\right)^{0.5}\left[\frac{N_{1}}{N_{2}} \frac{2 \pi R_{c}}{i_{o}}\right]\left[\frac{\rho_{2} \Delta H_{2}}{t_{Q B}}\right]^{0.5},
$$

where $\mathrm{R}_{\mathrm{QB}}$ is the resistance needed to induce quench-back in a time $\mathrm{t}_{\mathrm{QB}} \cdot \mathrm{N}_{1}$ is the number of turns in the coil; $N_{2}$ is the number of turns in the secondary $\left(N_{2}=1\right) ; R_{C}$ is the average radius of the coil; $i_{o}$ is the starting current $\left(i_{o}=275 \mathrm{~A}\right) ; \rho_{2}$ is the secondary circuit resistivity; and $\Delta \mathrm{H}_{2}$ is the enthalpy change per unit volume in the secondary circuit material (mandrel). When a magnet is designed to quench back the quench back time $\mathrm{t}_{\mathrm{QB}}$ is short ( $\sim \mathrm{s})$. The mandrel resistivity $\rho_{2}=1.42 \times 10^{-8} \Omega \mathrm{m}$. The design enthalpy change $\Delta \mathrm{H}_{2}$ for aluminum from $4 \mathrm{~K}$ to $10 \mathrm{~K}$ is $\sim 11700 \mathrm{~J} \mathrm{~m}^{-3}$.

The expression in equation 29 can be turned around in order to estimate the time that it would take to cause quench back a coil $\mathrm{t}_{\mathrm{QBC}}$ when there is an effective resistance $\mathrm{R}_{\text {eff }}$ across the coil. This expression is as follows;

$$
t_{Q B C}=\left(\frac{1}{\delta}\right)\left[\frac{N_{1}}{N_{2}} \frac{2 \pi R_{C}}{i_{o} R_{e f f}}\right]^{2} \rho_{2} \Delta H_{2}
$$

Table 10 shows the coil parameters, the coil decay time constant and the quenchback time for the three coil circuits for the spectrometer solenoid shown in Figure 14.

Table 10. The L/R time constant and Quench Back Time for the Three Circuits of the Spectrometer Solenoid that become separated when a Lead has Burned-out

\begin{tabular}{|l|c|c|c|}
\hline \multicolumn{1}{|c|}{ Parameter } & M1 & M2 & E1+C+E2 \\
\hline Circuit Self Inductance $(\mathrm{H})$ & 13.2 & 5.5 & 74 \\
\hline Effective Resistance $\mathrm{R}_{\text {eff }}(\mathrm{ohms})$ & 0.0344 & 0.0344 & 0.0474 \\
\hline L/R Circuit Time Constant $(\mathrm{sec})$ & 384 & 160 & 1561 \\
\hline Number of Coil Turns $\mathrm{N}_{1}$ & 4890 & 3192 & 22412 \\
\hline Average Coil Radius $\mathrm{R}_{\mathrm{C}}(\mathrm{m})$ & 0.281 & 0.273 & 0.274 \\
\hline Mandrel Resistivity $\rho_{2}(\mathrm{ohm}-\mathrm{m})$ & $1.42 \times 10^{-8}$ & $1.42 \times 10^{-8}$ & $1.42 \times 10^{-8}$ \\
\hline Mandrel Enthalpy Change $\left(\mathrm{J} \mathrm{m}^{-3}\right)$ & 11700 & 11700 & 11700 \\
\hline Coupling Coefficient $\delta$ & 0.91 & 0.92 & 0.92 \\
\hline Quench Back Time $(\mathrm{sec})$ & 152 & 60.4 & 1580 \\
\hline
\end{tabular}


The coil M2 will quench first. The quench will spread to coils M1 and E1 from the heating of coil M2. The whole magnet will quench within 10 to 15 seconds of the quench of coil M2. In Table 10, the resistor resistance is assumed to $0.015 \mathrm{ohms}$. The maximum resistance could be as large as $0.02 \mathrm{ohms}$. The effective resistance includes the back-toback diodes operating at a voltage drop of $1.2 \mathrm{~V}$ while carrying a current of $275 \mathrm{~A}$.

When a lead breaks, the M1 and M2 circuit resistances will produce $2600 \mathrm{~W}$ of heat (at $275 \mathrm{~A})$. The three-coil set resistance (E1, C, and E2) will produce $3580 \mathrm{~W}$ (at $275 \mathrm{~A}$ ). Each 304 stainless steel resistor produces $\sim 1130 \mathrm{~W}$ at $275 \mathrm{~A}$. The heat must be transferred to the surroundings. The heat transfer will be by combined free convection and radiation heat transfer. The resistors will reach their maximum temperature in $20 \mathrm{~s}$. The worst-case heat transfer will be by radiation only. The estimated heat transfer area per resistor is $\sim 0.00635 \mathrm{~m}^{2}$. If the heat transfer is by radiation only, the resistor temperature would reach a temperature of $\sim 1330 \mathrm{~K}(\sim 1060 \mathrm{C})$, which is more than enough to discolor and warp the stainless steel resistors. With combined radiation and convection heat transfer, the resistor temperature will be a little lower.

The IR heating from the resistors and diodes will put at least $527 \mathrm{~kJ}$ of heat into the cold mass before coil M2 quenches. The diodes and resistors are mounted on the outside of the banding for the center coil. Heating the center coil will speed up the quenching of the spectrometer solenoid by quenching the center coil of the three-coil string. LBNL should consider changing the design of the resistor pack in order to improve the heat flow from the resistors to the outside of the center coil banding. A change in the resistor pack design can also reduce the temperature of the resistors enough to eliminate insulation charring during a quench caused by a lead failure.

\section{b) Resistor Overheating due to the Power Supply being left on}

The diode forward voltage is between 1.0 and 1.5 volts depending on temperature. The higher the diode temperature, the lower the forward voltage. The six sets of back-toback diodes shown in Figure 12 will have a forward voltage from 6 to 9 volts. The power supply can deliver $10 \mathrm{~V}$. This means that there can be a current flowing through the diodes and the resistors. The diodes have enough surface area to be cooled using free convection. The 0.015 -ohm resistors, which have a smaller surface area, may not have the level of cooling that the diode packs have. As a result, over time the resistors might get hot enough to burn the insulation between the resistors and the cold mass cover plate.

Since the power supply can deliver up to $300 \mathrm{~A}$, there is enough capacity in the power supply to deliver a current to the resistor string at the level of 8 to 32 A depending on the diode string forward voltage. With the power supply left on after the quench, there is enough flowing through the string to produce from $7.2 \mathrm{~W}$ to $192 \mathrm{~W}$ of heating in the resistors. The diodes will produce an additional $7.2 \mathrm{~W}$ to $128 \mathrm{~W}$ of heating that is put into the cold mass. The overheating and charring of insulation that occurs depends on the voltage drop through the diodes and the amount of time the power supply is left on after the magnet has quenched. The maximum resistor temperature is $\sim 770 \mathrm{~K}(\sim 500 \mathrm{C})$.

The solution to this problem is simple, and yet it isn't simple. All one has to do is shut off the power supply after the quench occurs. In general this requires that some sort of electronic signal be measured. That signal turns off the power supply. A quench should be monitored using a data-logger. The data logger is needed to determine which coil in the spectrometer magnet triggered the quench of the magnet. 
In general, it is better to use a signal such as the pressure in the magnet cryostat as a trigger to turn off the power supply. The pressure can be measured mechanically, so one can turn off the power supply without using electronic systems that tend to be unreliable. Turning off the power supply should be regarded as an equipment safety issue.

Modifying the resistor pack will also eliminate the insulation charring when a lead failure occurs will also eliminate charring of the resistor insulation due to currents flowing in the resistors when the power supply be left on inadvertently.

\section{c) The Most Likely Cause of the Resistor Overheating}

The lead burnout appears to be the likely cause of the over heated resistor observed in magnet 2. During a lead failure, the maximum resistor temperature can be $\sim 1330 \mathrm{~K}$ $(\sim 1060 \mathrm{C})$. The maximum possible resistor temperature when the power supply is left on is $\sim 770 \mathrm{~K}(\sim 500 \mathrm{C})$. While one can make a case for both causes, one should look at the resistors of spectrometer solenoid 1. If the resistors in magnet 1 are not warped and discolored, the resistors in magnet 2 were most likely over heated when one of the leads burned out.

The Magnet 1 cold mass must be cut open in order to beef up the $1.3 \mathrm{~mm}$ diameter leads going to the feed through in the helium vessel. At this time the resistor and diode pack in Magnet 1 can be modified to match that of Magnet 2.

\section{d) Modification of the Diode and Resistor System to enhance Quench-back}

Changing the hook up of the resistors and diodes can bring more resistors into play should a magnet lead fail or if the magnet becomes disconnected from a power supply. The diode resistor packs that are currently in spectrometer magnets 1 and 2 only allow six of the nine resistors to be part of the quench process when a lead fails. A simple modification of the circuit shown in Figure 12 would allow eight of the nine resistors to become part of the quench process when a lead fails or any of the magnet coils become disconnected inadvertently. The ninth resistor comes into play when one part of the center coil turns normal before the second part of the center coil turns normal. This resistor may carry some current even if both the inner and outer turns of the magnet are normal. In other words, the ninth resistor acts as a load-balancing resistor between the resistors and diodes across the center coil.

The results of using eight resistors instead of six resistors during a lead failure are as follows: 1) The L/R time constant for the three-coil-set is reduced from $1560 \mathrm{~s}$ to $960 \mathrm{~s}$. 2) The estimated mandrel quench-back process for the three-coil-set alone is reduced from $1581 \mathrm{~s}$ to $593 \mathrm{~s}$. 3) The total heat that is produced by the diodes and resistors during the time that coil M2 is caused to quench due to quench-back increases from $527 \mathrm{~kJ}$ to about $662 \mathrm{~kJ}$ (assuming a constant $0.015 \mathrm{ohms}$ per resistor). As a result of all three factors, the process of quenching the spectrometer solenoid will be speeded up, when a lead fails. The quench process improvement is greatest for the three-coil-set. The heat generated by the three-coil-set resistors, when a lead fails, increases from about $3580 \mathrm{~W}$ to about $5840 \mathrm{~W}$ (assuming a constant resistance of $0.015 \Omega$ ).

The modified circuit for the resistor and diodes system for the spectrometer solenoid is shown in Figure 15. The system hook-up shown in Figure 15 is as it is when the magnet is connected using the three 300-A power supplies and the two 60-A power supplies called for in the original design. 


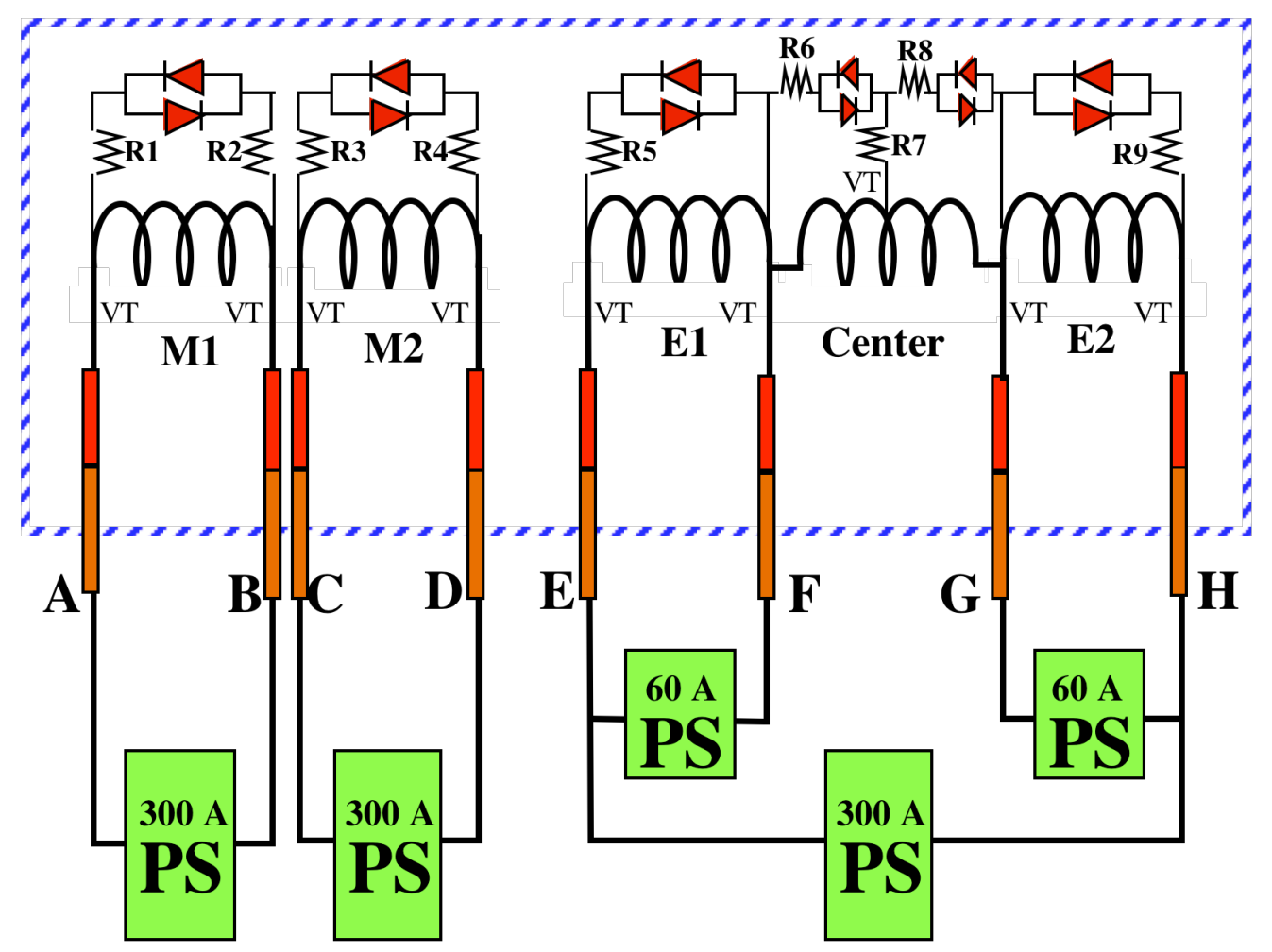

Figure 15. The Reconfigured Magnet Circuit that allows Two More Resistors to be connected across the Three-coil-set when a Lead Fails. (When the magnet has all five coils connected in series, there are eight resistors across causing the current to decay instead of six resistors. The only resistor not part of the magnet circuit, when a lead fails, is resistor R7.)

The resistors that are shown in Figure 11 are not very well connected to the magnet cold mass thermally. The resistors must heat up to a high temperature so that they can radiate away the energy put into the resistor by the current. It takes $\sim 20$ seconds before the resistors are hot enough to start warming the magnet cold mass. Half of the energy ends up in the helium tank shell. The helium tank shell is not very well connected to the coil packages. The rest of the energy will go into the magnet center coil banding, but it would be better if all of the energy ends up in the banding outside of the center coil.

The resistor and diode packages, which are in the helium tank, should be redesigned with two things in mind. They things are: 1) The heat flow into the center coil must be increased. 2) The time before the heat is transferred to the center coil must be reduced. A solution is to encapsulate the resistors between two ceramic plates. The ceramic plates should be attached to copper plates that will conduct the heat to the outside of the center coil banding. Encapsulating the resistors reduces the time needed to transfer the heat to the center coil. As a result, the center coil will quench sooner.

LBNL has a couple of choices. They can leave the resistor configuration as it is (see Figure 12) or the resistors can be reconfigured as shown in Figure 15. The author prefers the later solution. At the very least, the resistors can be boxed so that all of the energy radiated to the box from the resistors so that the thermal energy can be conducted to the cold mass. The current G-10 insulation should be replaced with a ceramic insulation. The author feels that it is OK to test the magnet with all five coils in series in either the six resistor configuration (Figure 12) or the eight resistor configuration (Figure 15). 


\section{Coil Voltage and Current Measurements and Other Issues}

\section{a) Coil Voltage and Current Measurements}

Ideally the charging voltage should be measured across the coils not at the power supply. This permits the voltage to be controlled at the coil level. Voltage control is particularly important for coils M1 and M2, which have only one set of diodes in series with the quench protection resistor. The maximum allowable charging or discharging voltage for coils M1 and M2 is $\sim 3$ volts [41]. The charging voltage for the three-coil set can be the full $10 \mathrm{~V}$ available, without firing the diodes. The correction power supply is limited to $\sim 3 \mathrm{~V}$. The voltage taps that are shown in Figure 13 can also be used to monitor the voltage at the coil level, the bottom of the HTS lead, the top of the HTS leads, and the room temperature leads in the air just outside of the feed-through. As the current in the magnet goes up the voltage drop to the power supply increases. There is less available voltage to charge the magnet. When the magnet is being discharged the voltage drop along the leads from the power supply helps speed up the discharge process.

Measurement of the current in the five coils may be critical issue for MICE. During the tests of magnets $2 \mathrm{~A}$ and $2 \mathrm{~B}$, the current and charging voltage were measured at the power supply. This may not be adequate. In general, there are two methods for measuring the current in the coils, calibrated current shunts or calibrated inductive current sensors. The latter type of sensor is attractive if they will operate in the stray magnetic field of the spectrometer solenoid. A shunt is temperature sensitive, but it can always be operated in the stray field of the magnet.

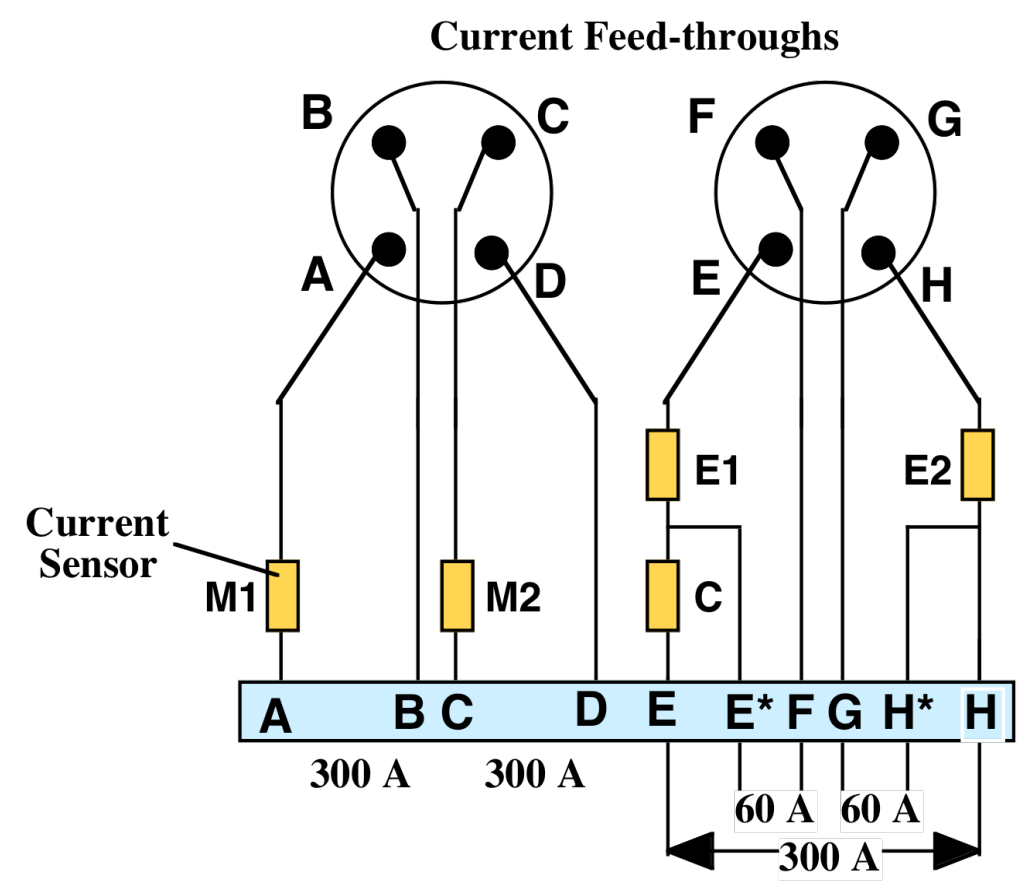

Figure 16. The Location of Current Sensors that will measure the Current in the Five Coils of the MICE Spectrometer Solenoid. (Note: the current from A to B applies for Coil M1. The current from C to D applies for coil M2. The current from $\mathrm{E}$ to $\mathrm{H}$ is the current for the center coil. The current in $\mathrm{E} 1$ is the current in the center coil plus the current from $\mathrm{E}^{*}$ to $\mathrm{F}$. The current in coil E2 is the current in the center coil plus the current from $\mathrm{G}$ to $\mathrm{H}^{*}$.) 
Figure 16 shows an arrangement of current sensors that can read the current in coils M1, M2, E1, C, and E2 directly. The sensors are in the lines that carry the currents for those coils. If redundancy is required a current sensors can be put into each of the lines shown in Figure 16. In general, the required level of the accuracy for the measurements of the currents in the magnet is about 0.1 percent.

It was originally thought that coils M1 for the two magnets could be connected in series. The two spectrometer magnets should not connected in series because the second magnet doesn't turn normal fast enough during a quench. Large unbalanced forces may occur. The quenching of the first magnet will cause the quench protection diodes in the second magnet to fire. The magnet will eventually quench, but the quench will be delayed by at least 30 seconds. The resistance of the quench protection resistors is too low for them to have a role of initiating quench back from the aluminum mandrels in both of the magnets [40].

The voltage in the taps across the coils (VTM-01 through VTM-09 in Figure 12), in the taps across the bottoms of the HTS leads (VTL-09 through VTL-16 in Figure 13), and the voltage in the taps across the tops of the HTS leads (VTL-01 through VTl-08 in Figure 13) should be recorded at intervals of $1 \mathrm{~ms}$ by using a data logger. This data can be used to find which coil started a magnet quench. The data logger can also record the voltage across the magnet HTS and LTS leads. This data may be very important in the event of an HTS lead failure.

\section{b) Some Other Magnet Safety Issues}

There were some safety issues from the recent tests on the magnet. The biggest safety issue is that one must climb on the magnet while filling the helium tank or doing any other work that requires access to the top of the magnet. A catwalk with railings on both sides of the magnet should be constructed so that people can safely work next to the magnet without having to get up on ladders or climb up on wooden boxes. Access to the catwalk may be a ladder that is part of the catwalk assembly.

The importance of policing the area around the magnet for objects made of ferromagnetic materials cannot be overstated. The stray field from the spectrometer solenoid is considerable. Care must be taken to make sure that only non-magnetic tools are used around the magnet when there is current in the coil. The primary hazard of magnetic field is the presence of ferromagnetic materials near the magnet.

All electrical connectors for cables, shunts and other electrical devices connected to the magnet power supply must be shielded so that people cannot handle the connections while the magnet is powered. The quench protection diodes alone will not protect a person from foolish acts.

\section{Concluding Comments}

This report makes a case for the cause of the failure of the M2 lead being caused by conductor motion. One can make a case for conductor motion because there was about a $300 \mathrm{~mm}$ length of unsupported wire that could have moved due to magnetic forces on the

wire. The section of the M2 lead that failed had an MPZ length that is less than $10 \mathrm{~mm}$. If $10 \mathrm{~mm}$ of this wire turns normal, the whole wire will turn normal rapidly at a velocity of over 3 meters per second. The MPZ length is inversely proportional to the current density in the wire and the resistivity of the matrix. The wire has a copper to 
superconductor ratio of 1.4. With a low copper to superconductivity ratio, the MPZ length is also reduced. At the time of the lead failure, the lead section that failed was in helium gas. Because the lead was in gas, there definitely wasn't enough cooling to this section of the M2 lead to prevent it from being burned out.

The author doesn't believe that the lead failure was caused by a magnet quench. Quenching the magnet may lead to a current surge, but the surge is not large enough to turn the lead normal. (A current surge must be over $1000 \mathrm{~A}$ and this is not possible.) The magnitude of this surge will be reported on in a future MICE note. Another argument against a quench of coil M2 being the cause of the failure is the time that it takes to burn out the lead. It takes about $4.4 \mathrm{~s}$ to burn out the wire at the full design current of the magnet. The burnout time at the current the lead failed is $\sim 5.5 \mathrm{~s}$. During a quench, the time constant for the current decay is of the order of $4 \mathrm{~s}$. The quench current decay time constant is too short for there to be sufficient integrated current squared with time to cause the lead to burn out in the way that it did. The author thinks that the lead being burned out led to the magnet quench. This is the same phenomenon that was observed when the HTS lead burned out in magnet 2A. Once current is shunted through the diodes and resistors, the magnet eventually quenches.

The lead that burned did not melt the solder in leads that were connected to the high current density lead that burned out. The melt time for the solder in the leads attached to the lead that burned out is longer than the time to burn out the high current density lead.

Cases 2, 3, and 4 represent the thickened leads back to the diodes and resistors, the pin of vacuum tight feed-through and the fixed section the magnet leads. All three of the cases are cryogenically stable in liquid helium even when the leads are insulated. The three cases are also cryogenically stable in helium gas as long as the gas temperature is less than $5.1 \mathrm{~K}$. The author strongly recommends that the cold mass liquid helium vessel be kept full of liquid helium when the spectrometer solenoid is operating.

The spreader outside the spectrometer solenoid cold mass vessel is in vacuum. The spreader rigidly supports the conductors that are connected to it. The conductors that are within the spreader are cooled by conduction to an aluminum plate that is welded to the helium tank. The author recommends that the conductors in the spreader be cooled from both sides rather than one side as was the case in magnets 1,2A and $2 \mathrm{~B}$. Cooling of the conductor after it leaves the either coupling coil or the focusing coils is very important. The current densities of these conductors should be as low as possible and the cooling surface should be maximized. Cooling the diodes and the resistors is also important in the coupling magnets and the focusing magnets. As long the conductor can be kept at a temperature below its critical temperature when the matrix is carrying the lead current, the conductor is cryogenically stable. The normal region will shrink and the conductor will become superconducting again.

The most likely cause of the overheating of the resistors in magnet 2 is that leads were burned out on two different occasions. Changes in the LTS lead design have eliminated this type of lead failure. The addition of a large GM cooler to cooler the copper plate that the tops of the HTS leads are connect to has greatly reduced the chance of an HTS lead failure. The only other fix for this situation is to re-design the resistors so that they have a larger surface are per unit resistance. It is also important that the resistor mass be roughly $2 \mathrm{~kg} \Omega^{-1}$. The G-10 insulation should be replaced by a ceramic insulation, so that the resistors don't burn the insulation, when a lead fails. 
There are sound arguments for making the resistors large enough to cause quench back in the coils in a reasonable amount of time (in $<2 \mathrm{~s}$ ). A larger resistance is allows the coils on one spectrometer solenoid to be connected in series with a like coil in the other spectrometer solenoid. This is clearly demonstrated in reference [40]. A large shunt resistance is not for MRI magnets, because MRI magnets operate in persistent mode with no leads to burn out. Larger resistors produce low peak voltages in the coils, and a lower hot spot temperature.

It is important that the power supply be turned off when any of the MICE magnets quench. This prevents the quench protection resistors and diodes from overheating after the quench. If possible, the power supplies should be disconnected from the magnet coils using a mechanical switch that is triggered by the cryostat pressure.

The configuration of the resistors and diodes in the magnet is a cause for concern. As the spectrometer magnets are currently configured (see Figure 12), only two resistors are in series with the diodes in the three-coil-set. This will delay the quenching of the magnet in the event of a lead failure. Increasing the number of resistors in series with the diodes in the three-coil-set from two to four will reduce the time before the magnet quenches when there is a lead failure. In addition the resistors should be encapsulated so that their temperature is reduced and so that heat from the resistors can be conducted to the center coil of the three-coil-set. This will speed up the quench process.

The accurate measurement of the coils currents may be important for the MICE experiment. The current and charging voltage measurements should be made at or near the coil. This means that the current transducers must be able to provide an accurate current measurement in the magnetic field. During normal magnet operating modes, care should be taken to see that the voltage across the internal diodes in the quench protection center be less than the forward voltage of the quench protection diodes. It is recommended that the maximum forward voltage per diode be kept below 3 volts.

The voltage taps on the coils, on the bottom of the HTS leads, and on the top of the HTS leads should be monitored by a data logger that can take measurements at a $1 \mathrm{~ms}$ intervals. This permits one to determine which coil quenched first in the event of a spectrometer magnet quench.

\section{Acknowledgment}

This work was also supported by the Office of Science of the US Department of Energy under DOE contract DE-AC-02-05CH11231.

\section{References}

[1] G. Gregoire, G. Ryckewaert, L. Chevalier, et al, "MICE and International Muon Ionization Experiment Technical Reference Document," http://www.mice.iit.edu, (2001).

[2] P. Fabbricatore, S. Farinon, M. Perrella, et al. "The Mechanical and Thermal Design for the MICE Detector Solenoid Magnet System, IEEE Transactions on Applied Superconductivity 15, No. 2, p 1255, (2005) MICE Note 110. http://www.mice.iit.edu.

[3] M. A. Green, C. Y. Chen, T. Juang et al, "Design Parameters for the MICE Tracker Solenoid," IEEE Transactions on Applied Superconductivity 17, No. 2, p 1247, (2007), MICE Note 158, http://www.mice.iit.edu. 
[4] S. T. Wang, R. Wahrer, C. Taylor, et al, "The Design and Construction of the MICE Spectrometer Solenoids," IEEE Transactions on Applied Superconductivity 19, No. 3 p 1348, (2009), MICE Note 236, http://www.mice.iit.edu.

[5] S. P. Virostek, M. A. Green, et al, "Preliminary Test Results for the MICE Spectrometer Superconducting Solenoids," IEEE Transactions on Applied Superconductivity 19, No. 3 p 1364 (2009), MICE Note 237, http://www.mice.iit.edu.

[6] S. P. Virostek, and M. A. Green, "The Results of Tests of the MICE Spectrometer Solenoids," to be published in IEEE Transactions on Applied Superconductivity 20, No. 3, p 377, (2010), MICE Note 279, http://www.mice.iit.edu.

[7] S. P. Virostek, M. A. Green, F. Trillaud, and M. S. Zisman "Fabrication, Testing, and Modeling of the MICE Superconducting Spectrometer Solenoids," Proceedings of IPAC10, Kyoto Japan, 23 to 28 May 2010, p 409, MICE Note 295, http://www.mice.iit.edu.

[8] M. A. Green, "What Happened with Spectrometer Magnet 2B." published as MICE Note 292, http://www.mice.iit.edu, LBNL-3927E, May 2010

[9] M. A. Green, S. P. Virostek and M. S. Zisman, "The Results of Recent MICE Superconducting Spectrometer Solenoid Tests," to be published in IEEE Transactions on Applied Superconductivity 21, No. 3, (2011), MICE Note 321, http://www.mice.iit.edu.

[10] M. A. Green, H. Wu, L. Wang, et al, "AC Losses in the MICE Channel Magnets, Is This a Curse of a Blessing?”, MICE Note 195, http://www.mice.iit.edu, LBNL-63804, Jan. 2008.

[11] Martin N. Wilson, Superconducting magnets, Chapter 8, pp 159-199, Oxford University Press, Oxford UK (1983)

[12] S. L.Wipf, and A. P. Martinelli, Proceedings of the 1972 Applied Superconductivity Conference, Anapolis MD, IEEE Conference Series, p 331 (1972)

[13\} S. L. Wipf, Los Alamos Scientific Laboratory Report LA-7275, (1978)

[14] Martin N. Wilson, Superconducting magnets, Chapter 5, pp 74-76, Oxford University Press, Oxford UK (1983)

[15] Martin N. Wilson, Superconducting magnets, Chapter 7, pp 145-156, Oxford University Press, Oxford UK (1983)

[16] W. H. Cherry and J. I. Gittlemen, "Thermal and Electrodynamic Aspects of the Superconductive Transition Process," Solid State Electronics 1, p 287 (1960)

[17] Alvin Tollestrup Fermi National Laboratory, private communication about 1975.

[18] P. H. Eberhard, M. Alston-Gernjost, M. A. Green, et al, "Quenches in Large Superconducting Magnets," Proceedings of MT-6, Bratislava Czechoslovakia, (1977).

[19] Z. J. J. Stekly and J. L. Zar, "Stable Superconducting Coils," IEEE Transactions on Nuclear Science NS-12, pp 367-375, (1965)

[20] Martin N. Wilson, Superconducting magnets, Chapter 6, pp 91-130, Oxford University Press, Oxford UK (1983)

[21] M. A. Green, "The Importance of Heat Transfer in the Stabilization of Superconductors," Proceedings of the International Conference on Magnet Technology MT-2, p 747, (1967).

[22] T. H. K. Frederking, "Peak Heat Flux and Temperature Difference in Nucleate Boiling of Liquefied Gases," Advances in Cryogenic Engineering 8, p 489, Plenum Press, New York, (1962)

[23] D. N. Lyon, "Boiling Heat Transfer and Peak Nucleate Boiling Fluxes in Saturated Liquid Helium between the $\lambda$ and Critical Temperatures," Advances in Cryogenic Engineering 10, p 371, Plenum Press, New York, (1964)

[24] E. G. Brentari, R. V. Smith, Nucleate and Film Pool Boiling Design Correlations for $\mathrm{O}_{2}$, $\mathrm{N}_{2}, \mathrm{H}_{2}$ and He," Advances in Cryogenic Engineering 10, p 325, Plenum Press, New York, (1964)

[25] M. A. Green, "Heat Transfer Correlations for Boiling and Convective Heat Transfer to a Liquid Helium Bath,” LRL Engineering Note 3913A, UCID 3050, August 1967 
[26] B. P. Breen and J. W. Westwater, Chem. Eng, Progress 38, No. 7, p 67, (1962)

[27] M. A. Green and S. Q. Yang, "The Effect of a Hydrogen Spill inside of a $300 \mathrm{~K}$ Vacuum Vessel on MICE Absorber Hydrogen Safety," MICE Note 100, http://www.mice.iit.edu (March 2004)

[28] M. A. Green, "Safety Issues for an Absorber that is Designed for Liquid Helium Operation as well as Liquid Hydrogen Operation, " MICE Note 113, http://www.mice.iit.edu (2005).

[29] V. D. Arp, R. D. McCarty, D. G. Friend, Thermophysical Properties of Helium-4 from 0.8 to $1500 \mathrm{~K}$ with Pressures to $2000 \mathrm{MPa}$, NIST Monograph 1334 (1989)

[30] Kirk D. Hagen, Heat Transfer with Applications, Prentice Hall, Upper Saddle River New Jersey, (1999)

[31] Frank Kreith, Principles of Heat Transfer, $4^{\text {th }}$ Edition, International Textbook Co., Scranton Pennsylvania (1961)

[32] S. S. Kutateladese, Inv. Akad. Nauk, USSR Otd.Tekh. Nauk, Vol. 4, p 529 (1951)

[33] M. A. Green and H. Witte, "Quench Protection and Magnet Power Supply Requirements for the MICE Focusing and Coupling Magnets," MICE Note 114, http://www.mice.iit.edu, LBNL-57580, June 2005

[34] Z. J. J. Stekly, "Theoretical and Experimental Study of an Unprotected Superconducting Coil Going Normal," Advances in Cryogenic Engineering 8, p 585, Plenum Press, New York, (1962)

[35] M. Scherer and P. Turowski, "Investigation of Propagation Velocity of a Normal Conducting Zone in Technical Superconductors," Cryogenics 18, p 515, September 1978

[36] P. H. Eberhard et al, "The Measurement and Theoretical Calculations of Quench Velocities in Large Fully Impregnated Superconducting Coils," IEEE Transactions on Magnetics MAG-17, No. 5, p 1803, (1981)

[37] M. A. Green, L. Wang, X. L. Guo, et al, "Quench Protection for the MICE Cooling Channel Coupling Magnet using Quench-back and Coil Sub-division, “ MICE Note 193, http://www.mice.iit.edu, November 2007

[38] X. L. Guo, M. A. Green, L. Wang, et al, "Quench Protection for the MICE Cooling Channel Coupling Magnet," IEEE Transactions on Applied Superconductivity 19, No.3, p 1360, MICE Note 235, http://www.mice.iit.edu, (2009)

[39] X. L. Guo, M. A. Green, L Wang, et al, "The Role of Quench-back in the Passive Quench Protection of Long Solenoids with Coil Sub-division," IEEE Transactions on Applied Superconductivity 20, No.3, p 2035, MICE Note 276, http://www.mice.iit.edu, (2010)

[40] X. L. Gou, M. A. Green, L. Wang, et al, "The Role of Quench-back in the Passive Quench Protection of Uncoupled Solenoids in Series with and without Coil Sub-division," to be published in IEEE Transactions on Applied Superconductivity 21, No.3, (2011), MICE Note 322, http://www.mice.iit.edu.

[41] Michael A. Green, "Design of a Rapid Discharge Varistor System for the MICE Magnet Circuits," MICE Note 208, (July 2008), http://www.mice.iit.edu.

[42] M. A. Green, "Design Conditions for Fail-safe Quenching of a High Current Density Superconducting Solenoid Magnet with a Shorted Secondary Circuit," LBNL-14859, September 1982.

[43] M. A. Green, "Quench-Back in Thin Superconducting Solenoid Magnets," Cryogenics 24, p 3, (January 1984)

[44] M. A. Green, "The Role of Quench-Back in Quench Protection of a Superconducting Solenoid, " Cryogenics 24, p 659, (December 1984) 


\section{DISCLAIMER}

This document was prepared as an account of work sponsored by the United States Government. While this document is believed to contain correct information, neither the United States Government nor any agency thereof, nor The Regents of the University of California, nor any of their employees, makes any warranty, express or implied, or assumes any legal responsibility for the accuracy, completeness, or usefulness of any information, apparatus, product, or process disclosed, or represents that its use would not infringe privately owned rights. Reference herein to any specific commercial product, process, or service by its trade name, trademark, manufacturer, or otherwise, does not necessarily constitute or imply its endorsement, recommendation, or favoring by the United States Government or any agency thereof, or The Regents of the University of California. The views and opinions of authors expressed herein do not necessarily state or reflect those of the United States Government or any agency thereof, or The Regents of the University of California. 